\title{
Seismic Imaging of Microblocks and Weak Zones in the Crust Beneath the Southeastern Margin of the Tibetan Plateau
}

\author{
Haijiang Zhang', Steve Roecker², Clifford H. Thurber ${ }^{3}$ and Weijun Wang4 \\ ${ }^{1}$ Department of Earth, Atmospheric, and Planetary Sciences, \\ Massachusetts Institute of Technology, Cambridge, MA \\ ${ }^{2}$ Department of Earth and Environmental Sciences, \\ Rensselaer Polytechnic Institute, Troy, New York \\ ${ }^{3}$ Department of Geoscience, University of Wisconsin-Madison, Madison, WI \\ ${ }^{4}$ Institute of Earthquake Science, China Earthquake Administration, Beijing, \\ $1,2,3$ USA \\ ${ }^{4}$ China
}

\section{Introduction}

The southeast margin of the Tibetan Plateau lies between the heartland of the plateau to the west and the stable south China block to the east, spanning from western Sichuan to central Yunnan in southwest China. Based on low-gradient topographic slope and lack of largescale young crustal shortening at the southeast plateau margin, Royden et al. (1997) and Clark and Royden (2000) proposed a channel-flow model in which a weak (low-viscosity) zone exists in the mid- to lower crust. Gravitational potential drives crustal materials from the Tibetan Plateau outward through the channel, creating a broad and topographically gentle margin and also accumulating stress near the strong crust of the Sichuan Basin. Using GPS data collected from the Crustal Motion Observation Network of China between 1998 and 2004, Shen et al. (2005) showed that the crust is fragmented into tectonic blocks of various sizes, separated by strike-slip and transtensional faults (Figure 1). They proposed a model for Tibetan Plateau deformation in which a mechanically weak lower crust experiences distributed deformation underlying a stronger, highly fragmented upper crust. On May 12, 2008, a destructive Ms 8.0 earthquake occurred along the Longmen Shan Fault, located between the eastern margin of the Tibetan Plateau and the Sichuan Basin (Burchfiel et al., 2008). It ruptured mainly toward the northeast over a length of $\sim 270 \mathrm{~km}$ along the northeast-trending fault, with coseismic slip mainly consisting of thrust- and right lateral strike-slip components (Wang et al., 2008b). No noticeable precursors were observed before the main shock, which was anticipated because GPS modeling showed very low right-slip $(\sim 1 \mathrm{~mm} / \mathrm{yr})$ and convergence $(<\sim 3 \mathrm{~mm} / \mathrm{yr})$ rates along the Longmen Shan boundary (Meade, 2007). A deep process involving channel flow is hypothesized to be responsible for the 2008 Wenchuan Ms 8.0 earthquake (Burchfiel, et al., 2008; Teng et al., 2008; Zhang et al., 2008). Other models than the channel flow model such as the block model were also proposed for causing this earthquake (e.g. Hubbard and Shaw, 2009). 
Regional seismic tomography studies using body waves (Huang et al., 2002; Wang et al., 2003; Wang et al., 2007; Huang et al., 2009; Xu and Song, 2010) and surface waves (Yao et al., 2008, 2010; Huang et al., 2010; Li et al., 2010) found widespread low velocity zones in the mid- and lower crust, supporting the channel-flow model proposed by Clark and Royden (2000). Receiver function analysis on stations in southwest China also identified low velocity zones (LVZs) in the mid- and lower crust and high average Poisson's ratio in the crust (e.g. $\mathrm{Xu}$ et al., 2007; Wang et al., 2008a; Liu et al., 2009; Zhang et al., 2009c). In addition, magnetotelluric (MT) sounding detected low resistivity layers in the middle and lower crust (e.g. Sun et al., 2003; Zhao et al., 2008; Bai et al., 2010). These low velocity and low resistivity zones were interpreted to be caused by partial melt.

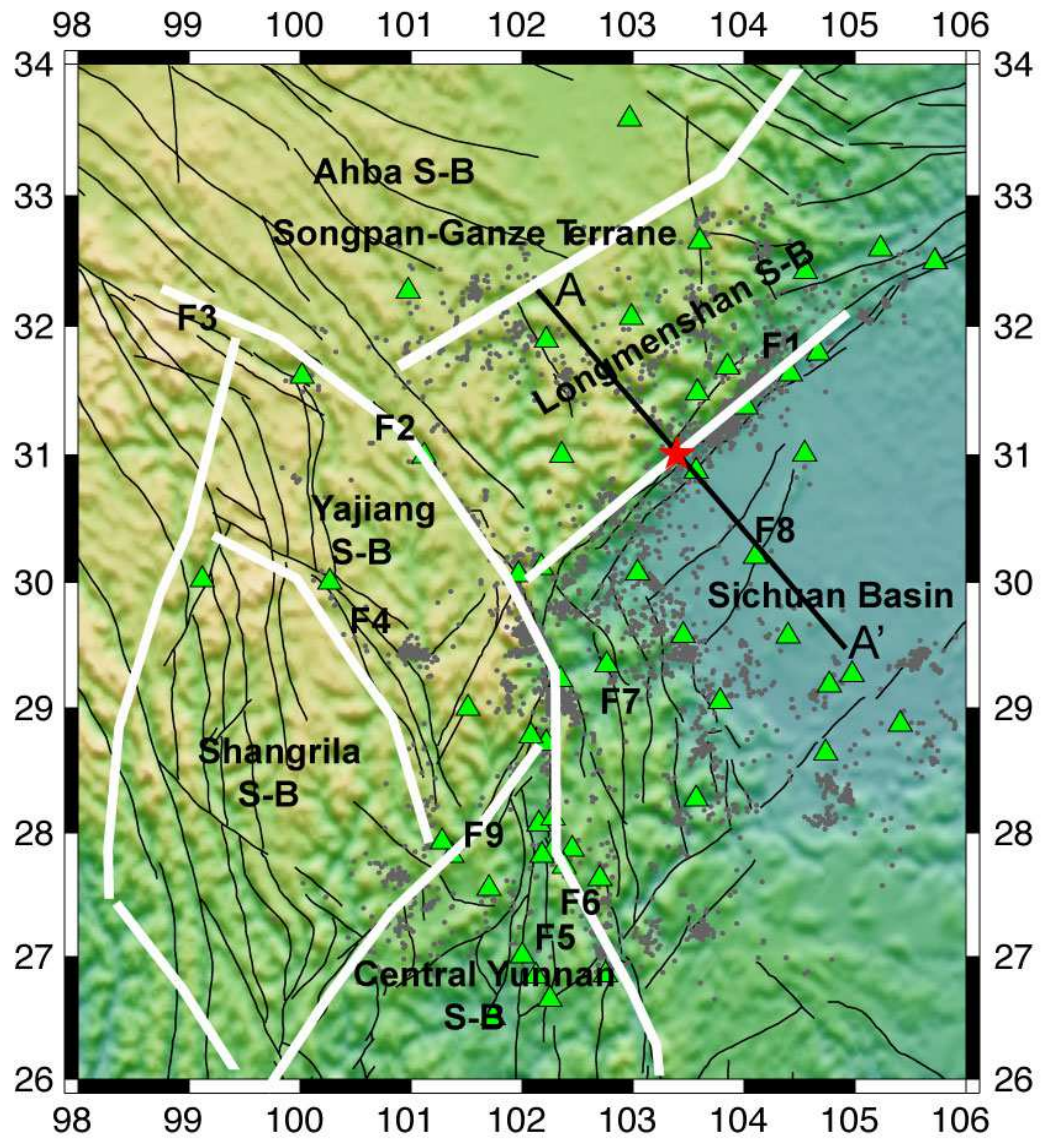

Fig. 1. Distribution of earthquakes (black dots) and stations (green triangles) for the study region. The black lines are mapped fault traces on surface. Red star indicates the 2008 Wenchuan Ms8.0 earthquake. White lines represent boundaries of deformation blocks from the surface GPS modeling (Shen et al., 2005). F1: Longmen Shan Fault; F2: Xianshuihe Fault; F3: Ganzi Fault; F4: Litang Fault; F5: Anninghe Fault; F6: Zemuhe Fault; F7: Daliangshan Fault; F8: Longquan Anticline; F9: Lijiang Fault. 
In this article, we present the results of a joint inversion for $\mathrm{Vp}, \mathrm{Vs}$, and $\mathrm{Vp} / \mathrm{Vs}$ models, applying a modified double-difference seismic tomography method to the catalog picks collected by the Seismological Bureau of Sichuan Province for the period 2001-2004. The joint interpretation of three models permits a more complete characterization of the mechanical properties and geological identity of crustal materials and therefore is helpful for better understanding the cause of the low velocity and low resistivity layers. Compared to the previous regional tomography studies in the Sichuan region, this is the first time that a $\mathrm{Vp} / \mathrm{Vs}$ model is directly inverted from $\mathrm{S}$ and $\mathrm{P}$ arrival times instead of from dividing $\mathrm{Vp}$ by Vs. The three-dimensional (3D) shear-wave velocity model of Yao et al. (2008) indicated that the LVZs vary considerably in strength and depth range and faults may mark lateral boundaries of the LVZs. Our high-resolution 3D Vp, Vs, and Vp/Vs models are utilized to examine the spatial distribution of and interconnectivity between LVZs, which is important for understanding the tectonic block motions (Shen et al., 2005). For accurately calculating ray paths and travel times between events and stations in the case of strong velocity heterogeneity, a spherical-earth finite-difference (SEFD) travel time calculation method is developed and tested.

\section{Spherical-Earth Finite-Difference (SEFD) travel time calculation}

Since their introduction to seismology by Vidale (1988), finite difference solutions to the eikonal equation have enjoyed widespread application as a robust and efficient technique for computing travel times in heterogeneous media. To the extent that one can easily access the travel time tables produced by such techniques, they can be readily incorporated into earthquake location and tomographic imaging algorithms (e.g. Nelson and Vidale, 1990; Hole, 1992). With few exceptions (Fowler, 1994; Schneider, 1995), these finite difference algorithms solve the Cartesian form of the eikonal equation:

$$
\left(\frac{d t}{d x}\right)^{2}+\left(\frac{d t}{d y}\right)^{2}+\left(\frac{d t}{d z}\right)^{2}=s^{2},
$$

where $s$ is the local slowness. To the extent that there is no significant spatial regularity in the heterogeneity that we are attempting to parameterize, the bias that we introduce by a particular choice of grid system, Cartesian or otherwise, will not be significant or in the worst case will increase the level of model noise.

As a simple consequence of gravity and temperature, wavespeeds in the earth are primarily a function of depth; lateral variations in wavespeed often tend to be only a few percent. Over regional distances on the order of $\sim 200 \mathrm{~km}$ or less, such depth variations should for most purposes be modeled adequately by a Cartesian grid. However, there is a potential for introducing a model induced signal into an inversion when at greater distances the radial variations in wavespeed do not correlate well with the Cartesian grid. One strategy for coping with sphericity is to employ earth flattening (e.g. Abers and Roecker, 1991) but the transformations for flattening are not appropriate for a laterally heterogeneous medium, and moreover there are issues with computing distance properly in the flattened frame (in particular they should always be computed along great circles). Another strategy is to simply put a round earth in a rectangular box, known as the sphere-in-a-box method (Flanagan et al., 2007), but this can artificially introduce anisotropy into the model because radial gradients are not represented the same way in all directions. Of course, such artifacts 
can be reduced by decreasing the grid spacing but resulting increase in the number of grid points could make the computations intractable.

As an alternative, one might consider solving the eikonal equation in a spherical coordinate system, so that radial gradients are parameterized equally throughout the model with a reduced number of grid points. The eikonal equation in spherical coordinates is:

$$
\left(\frac{d t}{d r}\right)^{2}+\left(\frac{1}{r} \frac{d t}{d \theta}\right)^{2}+\left(\frac{1}{r \sin \theta} \frac{d t}{d \phi}\right)^{2}=s^{2},
$$

where $r$ is the radius from center of the earth, $d r$ is positive away from the center, and $|d r|$ $=\mathrm{h} ; \theta$ is the co-latitude $\left(0^{\circ}\right.$ at north pole, $90^{\circ}$ at equator $), \mathrm{d} \theta$ is positive to the south, and $|\mathrm{d} \theta|=\Theta ; \phi$ is longitude, $\mathrm{d} \phi$ is positive to the east, and $|\mathrm{d} \phi|=\Phi$; and $\mathrm{s}$ is slowness.

To solve this system, we must be account for the differences in $r, \theta$, and $\phi$ for each node in the mesh. For each node $i$ we assign $r_{i}, \theta_{i}, \phi_{i}$, and also signs for directional purposes (Table 1). We derive expressions for each of the finite difference (FD) "stencils" used in the algorithm. For example, when applying Scheme A of Vidale (1990), we compute the time at one point given the times at 7 adjacent points in the 8-point cell.

\begin{tabular}{|c|c|c|c|c|c|c|c|}
\hline Point & Position & $\mathrm{r}$ & $\theta$ & $\phi$ & $\mathrm{r}$ Sign $(\mathrm{g})$ & $\theta$ Sign $(\mathrm{n})$ & $\phi$ Sign $(\mathrm{m})$ \\
\hline 0 & Deep SE & $\mathrm{r}_{1}$ & $\theta_{2}$ & $\phi_{2}$ & -1 & 1 & 1 \\
\hline 1 & Deep SW & $\mathrm{r}_{1}$ & $\theta_{2}$ & $\phi_{1}$ & -1 & 1 & -1 \\
\hline 2 & Deep NW & $\mathrm{r}_{1}$ & $\theta_{1}$ & $\phi_{1}$ & -1 & -1 & -1 \\
\hline 3 & Deep NE & $\mathrm{r}_{1}$ & $\theta_{1}$ & $\phi_{2}$ & -1 & -1 & 1 \\
\hline 4 & Shallow SE & $\mathrm{r}_{2}$ & $\theta_{2}$ & $\phi_{2}$ & 1 & 1 & 1 \\
\hline 5 & Shallow SW & $\mathrm{r}_{2}$ & $\theta_{2}$ & $\phi_{1}$ & 1 & 1 & -1 \\
\hline 6 & Shallow NW & $\mathrm{r}_{2}$ & $\theta_{1}$ & $\phi_{1}$ & 1 & -1 & -1 \\
\hline 7 & Shallow NE & $\mathrm{r}_{2}$ & $\theta_{1}$ & $\phi_{2}$ & 1 & -1 & 1 \\
\hline
\end{tabular}

Table 1. Convention on point numbering; the signs are the coefficients for the derivatives $\mathrm{dt} / \mathrm{dr}, \mathrm{dt} / \mathrm{d} \theta$, and $\mathrm{dt} / \mathrm{d} \phi$ as shown below.

Referring to Figure 2 and Table 1, the FD derivatives are:

$$
\begin{gathered}
\mathrm{dt} / \mathrm{dr}=\left[\left(\mathrm{t}_{4}-\mathrm{t}_{0}\right)+\left(\mathrm{t}_{5}-\mathrm{t}_{1}\right)+\left(\mathrm{t}_{6}-\mathrm{t}_{2}\right)+\left(\mathrm{t}_{7}-\mathrm{t}_{3}\right)\right] /(4 \mathrm{~h}) \\
1 / \mathrm{rdt} / \mathrm{d} \theta=\left[\left(\mathrm{t}_{0}-\mathrm{t}_{3}\right) / \mathrm{r}_{1}+\left(\mathrm{t}_{1}-\mathrm{t}_{2}\right) / \mathrm{r}_{1}+\left(\mathrm{t}_{4}-\mathrm{t}_{7}\right) / \mathrm{r}_{2}+\left(\mathrm{t}_{5}-\mathrm{t}_{6}\right) / \mathrm{r}_{2}\right] /(4 \Theta) \\
1 / \mathrm{r} \sin \theta \mathrm{dt} / \mathrm{d} \phi=\left[\left(\mathrm{t}_{0}-\mathrm{t}_{1}\right) /\left(\mathrm{r}_{1} \sin \theta_{2}\right)+\left(\mathrm{t}_{3}-\mathrm{t}_{2}\right) /\left(\mathrm{r}_{1} \sin \theta_{1}\right)+\left(\mathrm{t}_{4}-\mathrm{t}_{5}\right) /\right. \\
\left.\left(\mathrm{r}_{2} \sin \theta_{2}\right)+\left(\mathrm{t}_{7}-\mathrm{t}_{6}\right) /\left(\mathrm{r}_{2} \sin \theta_{1}\right)\right] /(4 \Phi)
\end{gathered}
$$

From these equations, it can be shown that the eikonal equation for this stencil is

$$
\begin{aligned}
\mathrm{s}^{2} & =\left[\sum_{\mathrm{i}=0}^{7} \mathrm{t}_{\mathrm{i}}^{2}+2 \sum_{\mathrm{i}=0}^{6} \mathrm{t}_{\mathrm{i}} \mathrm{g}_{\mathrm{i}} \sum_{j=\mathrm{i}+1}^{7} \mathrm{t}_{\mathrm{j}} \mathrm{g}_{\mathrm{j}}\right] / 16 \mathrm{~h}^{2}+\left[\sum_{\mathrm{i}=0}^{7}\left(\mathrm{t}_{\mathrm{i}} / \mathrm{r}_{\mathrm{i}}\right)^{2}+2 \sum_{\mathrm{i}=0}^{6} \mathrm{t}_{\mathrm{i}} \mathrm{n}_{\mathrm{i}} / \mathrm{r}_{\mathrm{i}} \sum_{j=\mathrm{i}+1}^{7} \mathrm{t}_{\mathrm{j}} \mathrm{n}_{\mathrm{j}} / \mathrm{r}_{\mathrm{j}}\right] / 16 \Theta^{2} \\
& +\left[\sum_{i=0}^{7}\left(\mathrm{t}_{\mathrm{i}} / \mathrm{r}_{\mathrm{i}} \sin \theta_{\mathrm{i}}\right)^{2}+2 \sum_{\mathrm{i}=0}^{6} \mathrm{t}_{\mathrm{i}} \mathrm{m}_{\mathrm{i}} / \mathrm{r}_{\mathrm{i}} \sin \theta_{\mathrm{i}} \sum_{j=\mathrm{i}+1}^{7} \mathrm{t}_{\mathrm{j}} \mathrm{m}_{\mathrm{j}} / \mathrm{r}_{\mathrm{j}} \sin \theta_{\mathrm{j}}\right] / 16 \Phi^{2}
\end{aligned}
$$




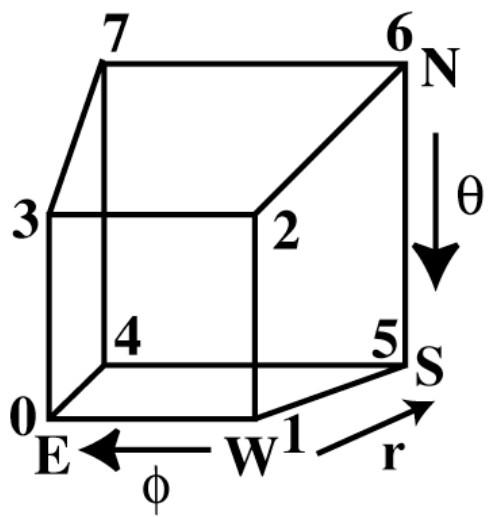

Fig. 2. Geometry of a basic cell for the spherical-earth FD calculation of travel times.

Given the values for $t_{0}$ through $t_{6}$, this expression can be rewritten in the form $a_{7} 7^{2}+b_{7}+c=$ 0 to solve for $t_{7}$, with coefficients $\mathrm{a}, \mathrm{b}$ and $\mathrm{c}$ defined as follows:

$$
\begin{aligned}
a= & \left(\frac{1}{h}\right)^{2}+\left(\left(\frac{1}{\Theta}\right)^{2}+\left(\frac{1}{\sin \theta_{7} \Phi}\right)^{2}\right) / r_{7}^{2} \\
b= & \left.2 \sum_{j=0}^{6} t_{j}\left(g_{7} g_{j} / h^{2}+n_{j} / \Theta^{2}+m_{7} m_{j} /\left(\sin \theta_{7} \sin \theta_{j} \Phi^{2}\right)\right) / r_{j} r_{7}\right) \\
c= & \sum_{i=0}^{6}\left(t_{i}^{2}\left(\frac{1}{h^{2}}+\left(\frac{1}{\Theta^{2}}+\left(\frac{1}{\sin \theta_{i} \Phi}\right)^{2}\right) / r_{i}^{2}\right)\right)+ \\
& 2 \sum_{i=0}^{5} t_{i} \sum_{j=i+1}^{6} t_{j}\left(g_{i} g_{j} / h^{2}+\left(n_{i} n_{j} / \Theta^{2}+m_{i} m_{j} / \sin \theta_{i} \sin \theta_{j} \varphi^{2}\right) / r_{i} r_{j}\right)-16 s^{2}
\end{aligned}
$$

Comparable equations, which are included in the Appendix, can be derived for the "edge" and "face" stencils of Vidale (1990).

One of the problems encountered with these finite difference techniques is that the travel times at the grid points in the immediate neighborhood of the starting point need to be assigned somehow. As long as the wavespeeds are not overly heterogeneous near the starting point, integration of slowness along a straight line path provides a reasonable estimate of travel time. This may not always be the case, however, and in any event as Vidale (1988) pointed out the finite difference approach does not work well when there is significant wavefront curvature over the size of the grid volume element. One efficacious way to solve both of these problems is to use a cascading approach by defining a fine grid in 
the vicinity of the starting point and a coarser grid outside that region. We have adopted this approach.

We tested the SEFD method by calculating travel times in an analytical velocity model $V=V_{0}$ $\left(r_{0} / r\right)$, where $V_{0}=4.0 \mathrm{~km} / \mathrm{s}, r_{0}$ is the Earth's radius and $\mathrm{r}$ is the distance between the source and the Earth's surface. Figure 3a shows the analytical travel times for a source located at latitude $21.2^{\circ}$ and longitude $121.75^{\circ}$. We discretized the model into a 3D grid with a grid interval of $0.1^{\circ}$ in latitude and longitude and $10 \mathrm{~km}$ in depth. The source region is set up to be 3 grid nodes in which the travel times are calculated along a straight-line path. The differences in travel times compared to analytic times are shown in Figure 3b. The travel time error around the source is as much as $1.08 \mathrm{~s}$. Outside the source region, the mean travel time error is $0.108 \mathrm{~s}$, and is everywhere generally smaller than $0.3 \mathrm{~s}$. Along the latitude

(a)

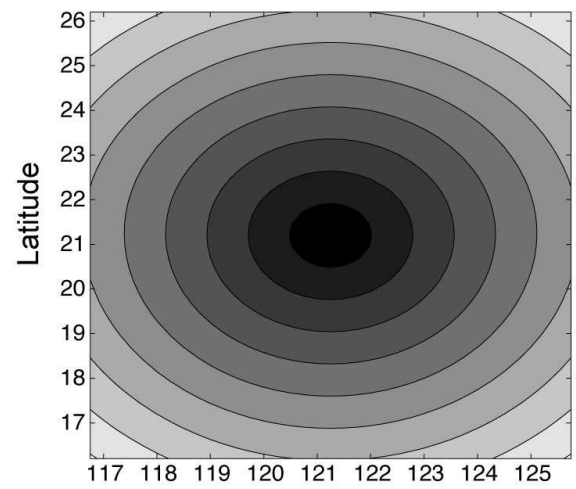

(c)
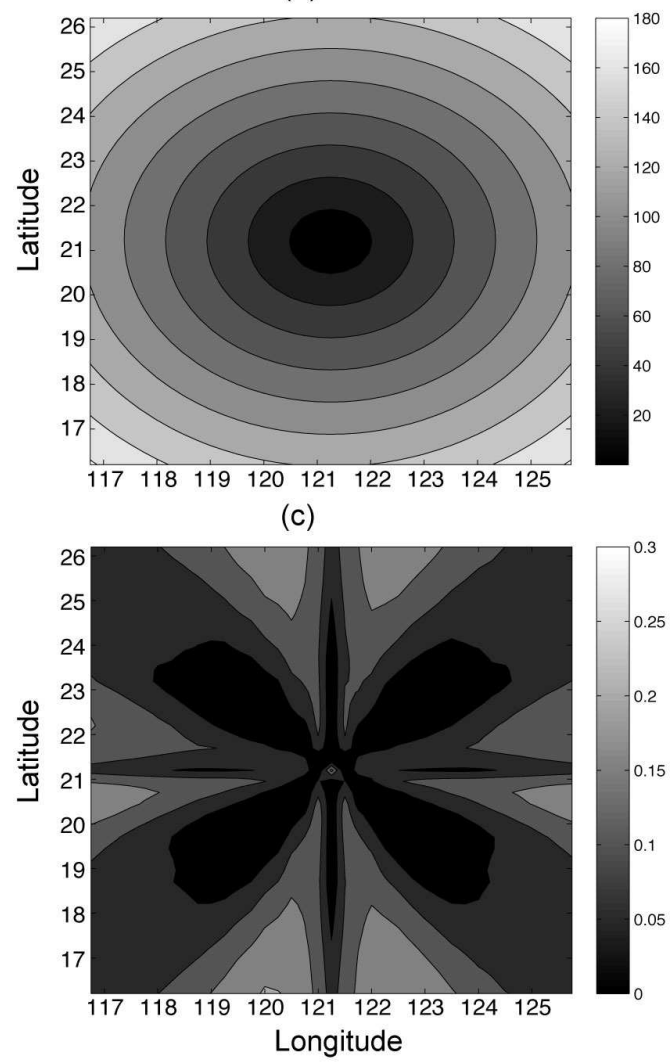

(b)

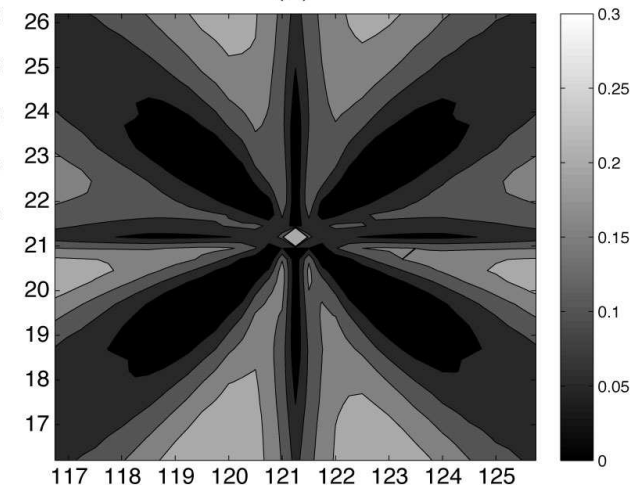

(d)

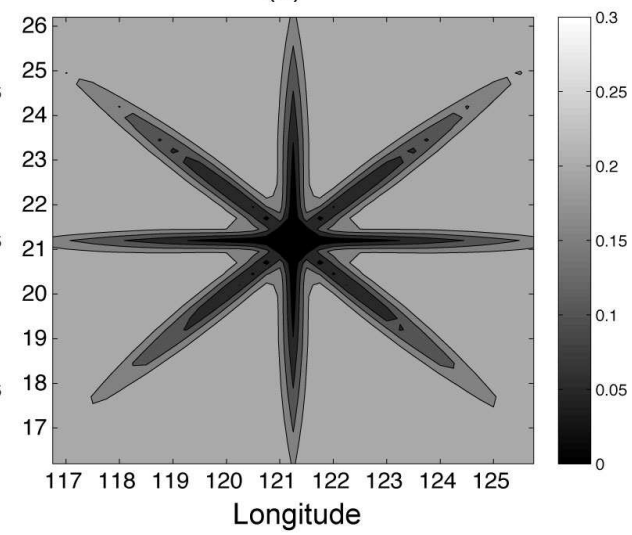

Fig. 3. (a) Analytic travel times from a source located at latitude $21.2^{\circ}$ and longitude $121.75^{\circ}$. (b) Travel time errors for the SEFD method. The spherical grid intervals are $0.1^{\circ}$ in latitude and longitude and $10 \mathrm{~km}$ in depth. (c) Travel time errors for the multi-grid SEFD method. The grid intervals are $0.01^{\circ}$ in latitude and longitude and $1 \mathrm{~km}$ in depth around the source region. (d) Travel time errors from the FD travel time calculation method in Cartesian coordinates. The time unit is second. 
and longitude directions and the directions between them, the travel time errors are relatively small due to the design of the stencils. To deal with the inaccuracy problem near the source region, we applied a cascading-grid strategy, in which a fine grid is used near the source region and a coarse one is used outside the source region. The grid interval inside the source region is 10 times smaller than that outside. The resulting travel time error near the source is much smaller than before, down to $0.17 \mathrm{~s}$ and the mean travel time error decreases to $0.087 \mathrm{~s}$. The tests show that the cascading-grid strategy improves the travel time accuracy near the source region and can also decrease the travel time error away from the source region. We also calculated the travel times using the "sphere-in-abox" method, in which the travel times are calculated on a 3D Cartesian grid with a uniform grid interval using the finite-difference eikonal solver of Podvin and Lecomte (1991). The velocity values on Cartesian grid nodes are linearly interpolated from 8 surrounding spherical grid nodes. The grid interval is set to be $5 \mathrm{~km}$, about 2 times smaller than that used for the SEFD travel time calculation. The travel time errors from Cartesian grid FD method are plotted in Figure 3d. It can be seen that the travel time errors around the source region are small. This is because the FD scheme used in Podvin and Lecomte (1991) adopted an initialization procedure to accurately calculate the travel times around the source. Similar to our SEFD method, the travel time errors are small along latitude, longitude and their middle intersections. However, the travel time errors outside the source region are relatively large. The overall mean travel time error is $0.312 \mathrm{~s}$, much greater than $0.108 \mathrm{~s}$ and $0.087 \mathrm{~s}$ for the two SEFD cases. This is mainly due to the inaccuracy in velocity values on Cartesian grid nodes when they are interpolated from the exact spherical grid nodes. Even when the Cartesian grid interval is finer, the travel time errors are still greater compared to the case using spherical grid.

\section{Seismic tomography method}

We employed a new version of the double-difference (DD) seismic tomography method that simultaneously solves for $\mathrm{Vp}, \mathrm{Vs}, \mathrm{Vp} / \mathrm{Vs}$ and event locations using both absolute and differential P, S, and S-P times (Zhang, 2003; Zhang et al., 2009a, b). This new code, named tomoDDPS, avoids the pitfalls of inferring $\mathrm{Vp} / \mathrm{Vs}$ from $\mathrm{Vp}$ and $\mathrm{Vs}$ models via division (Eberhart-Phillips, 1990). We briefly summarize the method as follows.

The $\mathrm{P}$ and $\mathrm{S}$ arrival times $T_{p}$ and $T_{s}$ from an earthquake $i$ to a seismic station $k$ are expressed using ray theory as path integrals

$$
\begin{aligned}
& T_{p k}^{i}=\tau^{i}+\int_{i}^{k} u_{p} d l \\
& T_{s k}^{i}=\tau^{i}+\int_{i}^{k} u_{s} d l
\end{aligned}
$$

where $\tau^{i}$ is the origin time of event $i, u_{p}$ and $u_{s}$ are the P- and S-wave slowness fields and $d l$ is an element of path length. The source coordinates $\left(x_{1}, x_{2}, x_{3}\right)$, origin times, ray paths, and the slowness field are the unknowns. By assuming the ray paths of $\mathrm{P}$ and $\mathrm{S}$ waves are identical, which is true when $\mathrm{Vp} / \mathrm{Vs}$ is constant, $\mathrm{Vp} / \mathrm{Vs}$ can be determined from S-P arrival times Ts-Tp, as follows (Thurber, 1993),

$$
\mathrm{T} s-\mathrm{T} \mathrm{p}=\int_{\text {path }}\left(\frac{\mathrm{V}_{\mathrm{p}}}{\mathrm{V}_{\mathrm{s}}}-1\right) \frac{\mathrm{d} l}{\mathrm{~V}_{\mathrm{p}}} .
$$


Note here because $\mathrm{P}$ and $\mathrm{S}$ waves from the same event share the same origin time, the unknown origin times are removed from this equation. In the simul2000 algorithm (Thurber and Eberhart-Phillips, 1999), Equations (6) and (8) are used to solve for Vp and Vp/Vs using $\mathrm{P}$ and S-P times and Vs is later calculated by dividing Vp by Vp/Vs. However, as noted by Wagner et al. (2005), the Vs model may be biased if calculated in this way because the anomaly in $\mathrm{Vp}$ may leak into Vs. In the new tomoDDPS algorithm, Vp, Vs, and Vp/Vs are determined simultaneously in a system using P, S, and S-P times based on Equations (6), (7) and (8) (Zhang, 2003; Zhang et al., 2009a, b). To meet the assumptions made for Equation (8), only S-P times from similar $\mathrm{P}$ and $\mathrm{S}$ ray paths are selected to solve for $\mathrm{Vp} / \mathrm{Vs}$.

Similar to the DD tomography code tomoDD, differential $\mathrm{P}$ and $\mathrm{S}$ times are also used in tomoDDPS to better constrain seismic event locations and Vp and Vs models (Zhang and Thurber, 2003). In addition, differential S-P times are also used to determine the $\mathrm{Vp} / \mathrm{Vs}$ structure based on the differential time version of Equation (8), which can be directly constructed from differential $\mathrm{P}$ and $\mathrm{S}$ times. One advantage of using differential S-P times is to remove the effect of different ray paths of $\mathrm{P}$ and $\mathrm{S}$ waves outside the source region. Near the source region, P- and S-wave ray paths are generally close to each other. Smoothing weights are applied to $\mathrm{P}$ - and S-wave slowness perturbations and $\mathrm{Vp} / \mathrm{Vs}$ perturbations for neighboring inversion grid nodes to stabilize the tomographic inverse problem. The complete tomographic system is represented as follows (Zhang et al., 2009a):

$$
\begin{cases}w_{1} d r_{k}^{i}=w_{1}\left(\sum_{l=1}^{3} \frac{\partial T_{k}^{i}}{\partial x_{l}} \Delta x_{l}^{i}+\Delta \tau_{i}+\int_{i}^{k} \delta u d s\right) & \text { Absolute S or P data } \\ w_{2} d r_{k}^{i, j}=w_{2}\left(\sum_{l=1}^{3} \frac{\partial T_{k}^{i}}{\partial x_{l}} \Delta x_{l}^{i}-\sum_{l=1}^{3} \frac{\partial T_{k}^{j}}{\partial x_{l}} \Delta x_{l}^{j}+\Delta \tau_{i}-\Delta \tau_{j}+\int_{i}^{k} \delta u d s-\int_{j}^{k} \delta u d s\right) & \text { Differential S or P data } \\ w_{3} d r_{k S P}^{i}=w_{3}\left(\sum_{l=1}^{3}\left(\frac{\partial T_{k S}^{i}}{\partial x_{l}}-\frac{\partial T_{k P}^{i}}{\partial x_{l}}\right) \Delta x_{l}^{i}+\int_{i}^{k} \delta\left(V_{p} / V_{s}\right) d s / V_{p}\right) & \text { Absolute S - P data } \\ w_{4} d r_{k}^{i, j} S P=w_{4}\left(\sum_{l=1}^{3}\left(\frac{\partial T_{k S}^{i}}{\partial x_{l}}-\frac{\partial T_{k P}^{i}}{\partial x_{l}}\right) \Delta x_{l}^{i}-\sum_{l=1}^{3}\left(\frac{\partial T_{k S}^{j}}{\partial x_{l}}-\frac{\partial T_{k P}^{j}}{\partial x_{l}}\right) \Delta x_{l}^{j}\right. & \text { Differential S - P data } \\ \left.+\int_{i}^{k} \delta\left(V_{p} / V_{s}\right) d s / V_{p}-\int_{j}^{k} \delta\left(V_{p} / V_{s}\right) d s / V_{p}\right) & \\ w_{5}\left(\delta u_{m}-\delta u_{n}\right)=0 & 1^{s t} \text { order smoothing of slowness perturbation } \\ w_{6}\left(\delta\left(V_{p} / V_{s}\right)_{m}-\delta\left(V_{p} / V_{s}\right)_{n}\right)=0 & 1^{s t} \text { order smoothing of Vp / Vs perturbation }\end{cases}
$$

where $d r_{k}^{i}=\left(T_{k}^{i}\right)^{o b s}-\left(T_{k}^{i}\right)^{c a l}$ is the absolute time residual, $d r_{k}^{i j}=\left(T_{k}^{i}-T_{k}^{j}\right)^{o b s}-\left(T_{k}^{i}-T_{k}^{j}\right)^{c a l}$ is the differential time residual, $\Delta \tau$ is the origin time perturbation, $\delta u$ is the $\mathrm{P}$ or $\mathrm{S}$ slowness perturbation, $\delta(V p / V s)$ is the $\mathrm{V}_{\mathrm{p}} / \mathrm{V}_{\mathrm{s}}$ perturbation, $w_{1}$ and $w_{2}$ are data weights for the absolute and differential $\mathrm{P}$ or $\mathrm{S}$ data, $w_{3}$ and $w_{4}$ are data weights for the absolute and differential S-P data, $w_{5}$ and $w_{6}$ are smoothing weights for slowness and $\mathrm{V}_{\mathrm{p}} / \mathrm{V}_{\mathrm{s}}$ models, and $\mathrm{m}$ and $\mathrm{n}$ indicate neighboring inversion grid nodes. The complete system is solved using a 
damped least squares inversion method LSQR in which the weighted data residuals are minimized (Paige and Saunders, 1987).

\section{Data and inversion details}

For the Sichuan region, we collected $\sim 38,600 \mathrm{P}$ - and $\sim 36,500 \mathrm{~S}$-wave first arrival times from 4878 earthquakes observed on 55 stations for the period 2001 to 2004 (Figure 1). These arrival times are selected from the original catalog data based on the major trend of travel time curves (Figure 4). There are obvious 60-second clock shift errors and other reading errors in catalog picks. For each event included in the analysis, there are at least $6 \mathrm{P}$ and $2 \mathrm{~S}$ observations, increasing the likelihood of reliable relocations. From the absolute P and $\mathrm{S}$ arrival times, we constructed $\sim 269,000 \mathrm{P}$ and $\sim 261,000 \mathrm{~S}$ differential times. The average number of differential times (links) per event pair is 11 and the average hypocentral separation (based on catalog locations) for the linked event pairs is $\sim 11 \mathrm{~km}$.

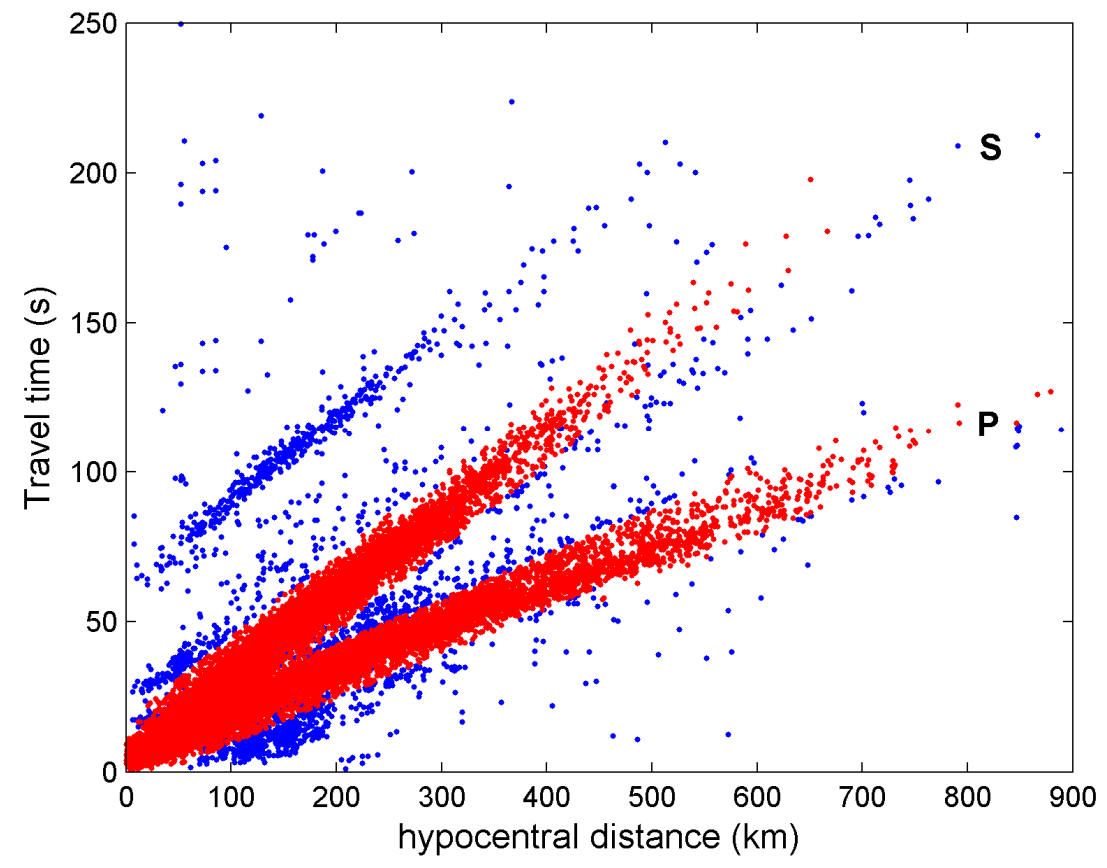

Fig. 4. P and S travel time curves for the original (blue) and selected (red) catalog data.

The inversion grid interval for the velocity model in latitude and longitude is $0.5^{\circ}$. In depth, the grid nodes were positioned at $0,5,10,17.5,25,35,45,65$, and $90 \mathrm{~km}$. In the Sichuan region, the Moho depth varies from $\sim 60 \mathrm{~km}$ in the Songpan-Ganze terrane to $\sim 46 \mathrm{~km}$ in the Sichuan basin (Xu et al., 2007). Therefore our model mainly reflects the crustal structure of the southeastern Tibetan Plateau. We first derived a minimum one-dimensional (1D) velocity model for the region based on the regional 1D velocity model of Zhao et al. (1997) 
(Figure 5). The travel times were calculated using the new SEFD method described above. Both damping and first-order smoothing were used to stabilize the inversion. A trade-off analysis between data variance and model variance was used to select optimum damping and smoothing parameters. The initial unweighted root-mean-square (RMS) travel time residual of $1.78 \mathrm{~s}$ was reduced to a final value of $0.48 \mathrm{~s}$, a reduction of approximately $73 \%$. We assess the model quality by a checkerboard resolution test. $\pm 5 \%$ velocity anomalies were added to the final 3D Vp and Vs models with an anomaly size of one grid node (Figures 6 and 7). The velocity anomalies for $\mathrm{Vp}$ and $\mathrm{Vs}$ are made opposite in sign so that the $\mathrm{Vp} / \mathrm{Vs}$ anomaly ranges from approximately $-9 \%$ to $11 \%$ (Figure 8 ). A combination of constant noise for each station and random noise at a level comparable to the final inversion misfit is added to the absolute $\mathrm{P}$ and $\mathrm{S}$ times. The checkerboard resolution test showed that both $\mathrm{Vp}$ and Vs models are relatively well resolved for the depth range of 5 to $65 \mathrm{~km}$ except for the depth slice of $17.5 \mathrm{~km}$. For the Vp/Vs model, it is also well resolved from a depth of 5 to $45 \mathrm{~km}$ except for the depth slice of $17.5 \mathrm{~km}$. For the depth slice of $65 \mathrm{~km}$, the $\mathrm{Vp} / \mathrm{Vs}$ model has some resolution in the middle part of the model. All three models have poor resolution at depth $0 \mathrm{~km}$.

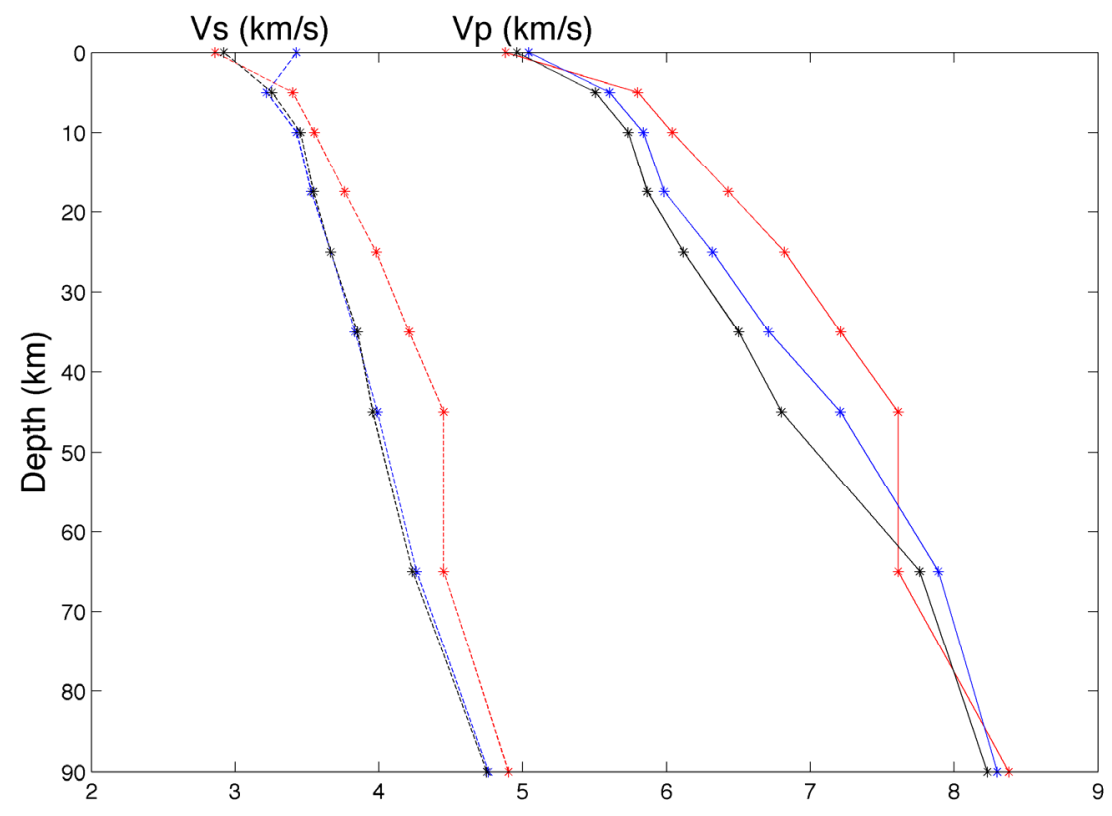

Fig. 5. Three different 1D Vp and Vs profiles for the Sichuan region. RRed: the 1D model of Zhao et al. (1997); Blue: the inverted 1D model; Black: the average 1D model from the 3D inverted model. 

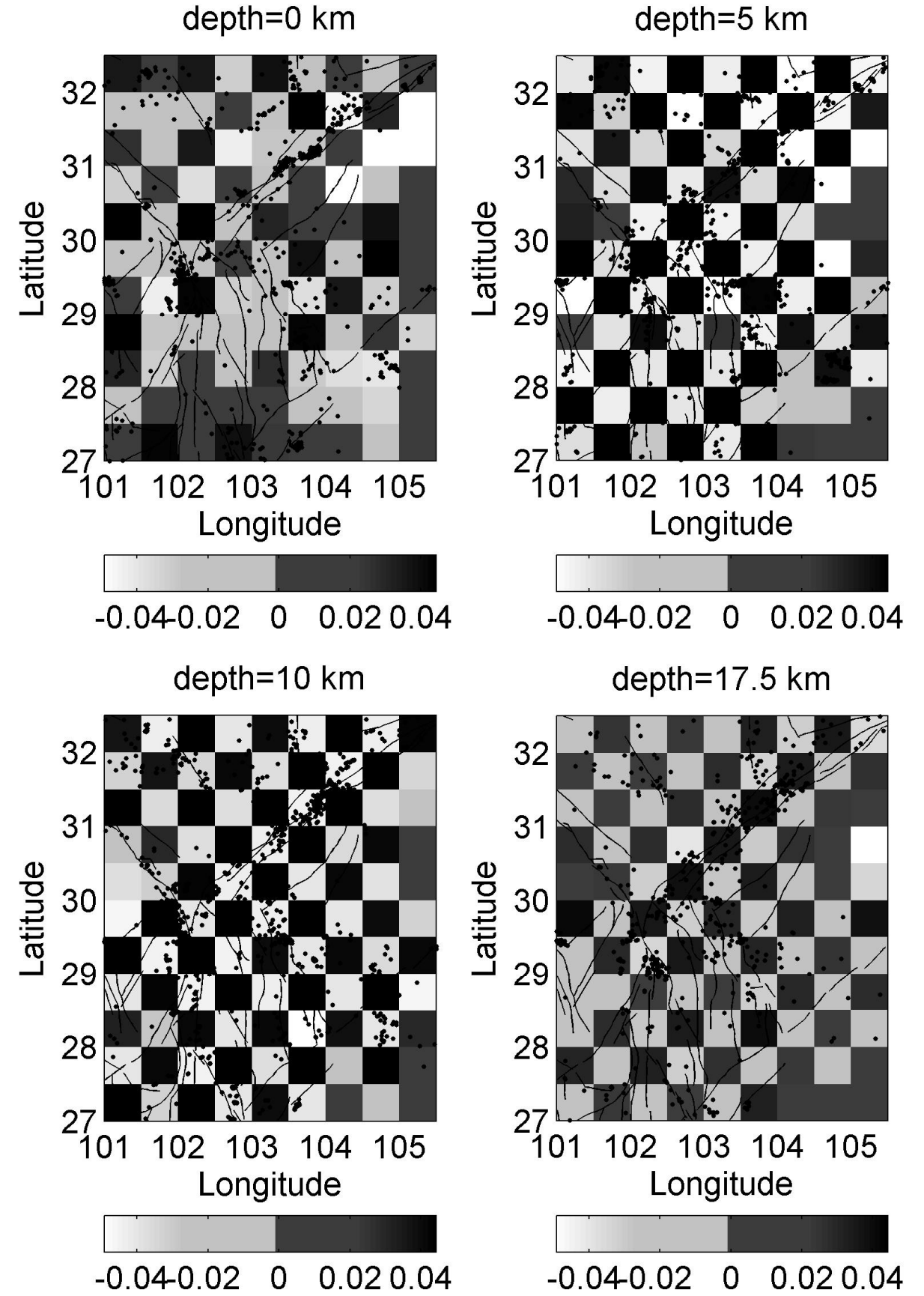

Fig. 6. Horizontal slices of the recovered Vp checkerboard model. 

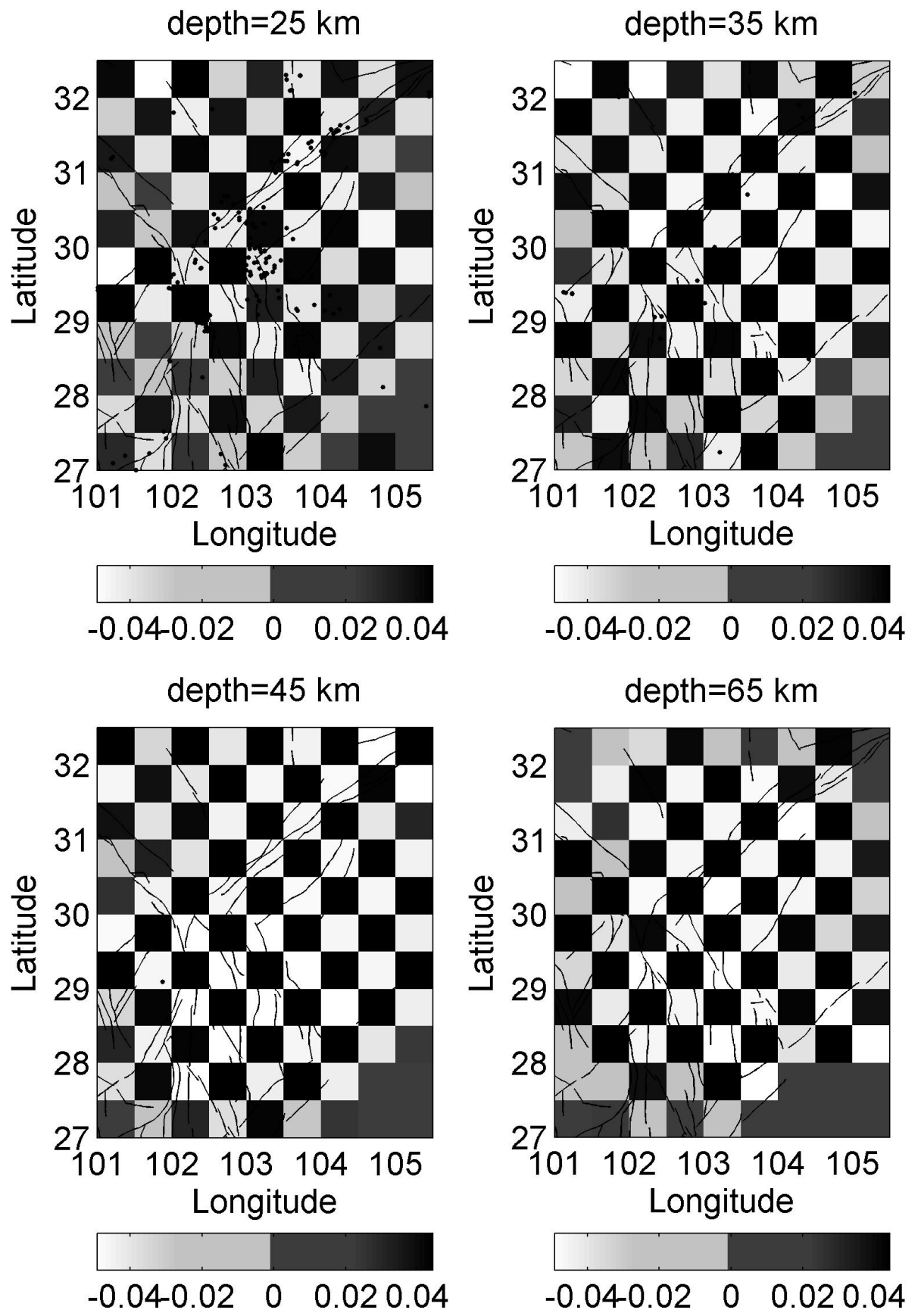

Fig. 6. (Continued) 

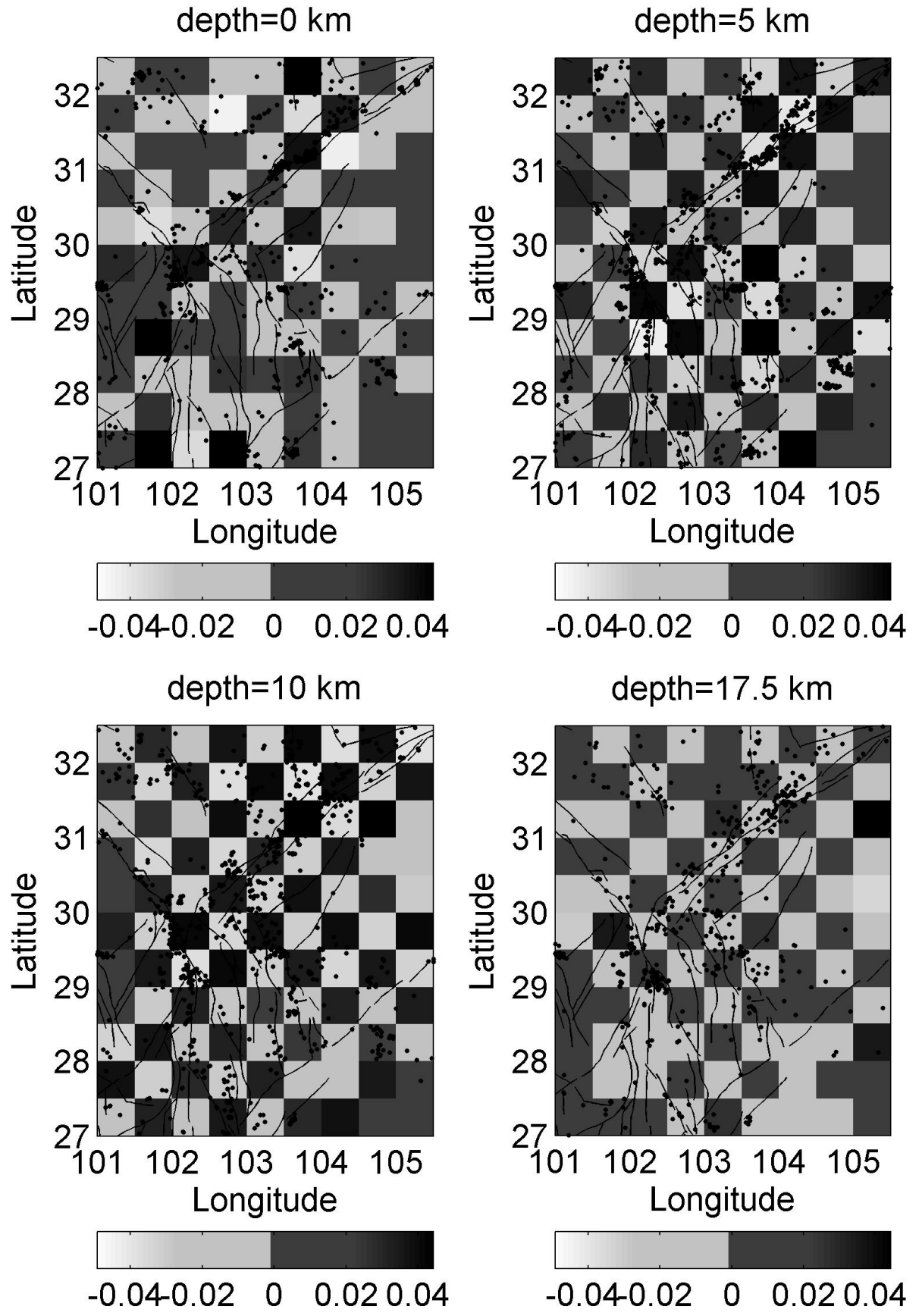

Fig. 7. Horizontal slices of the recovered Vs checkerboard model. 

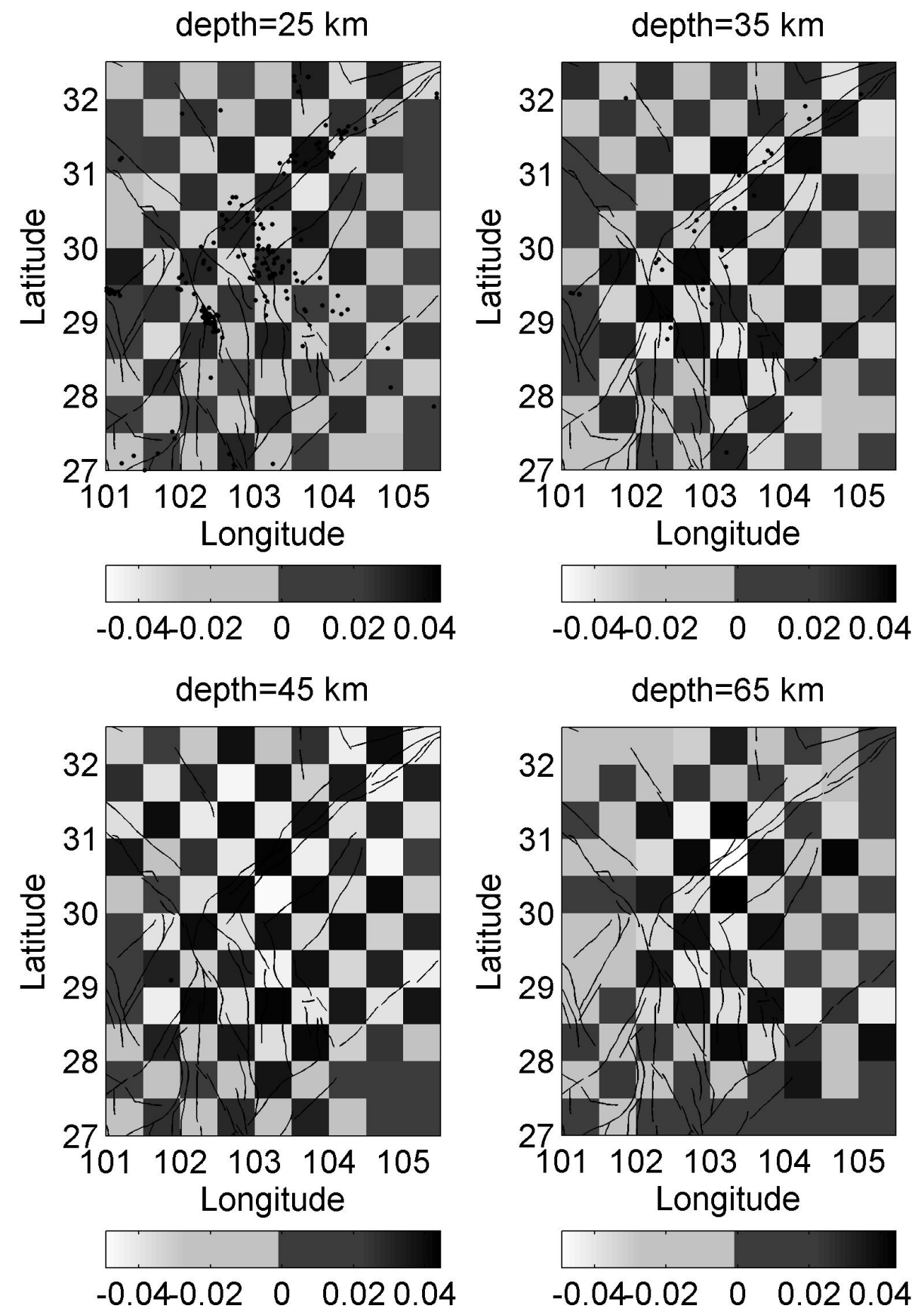

Fig. 7. (Continued) 

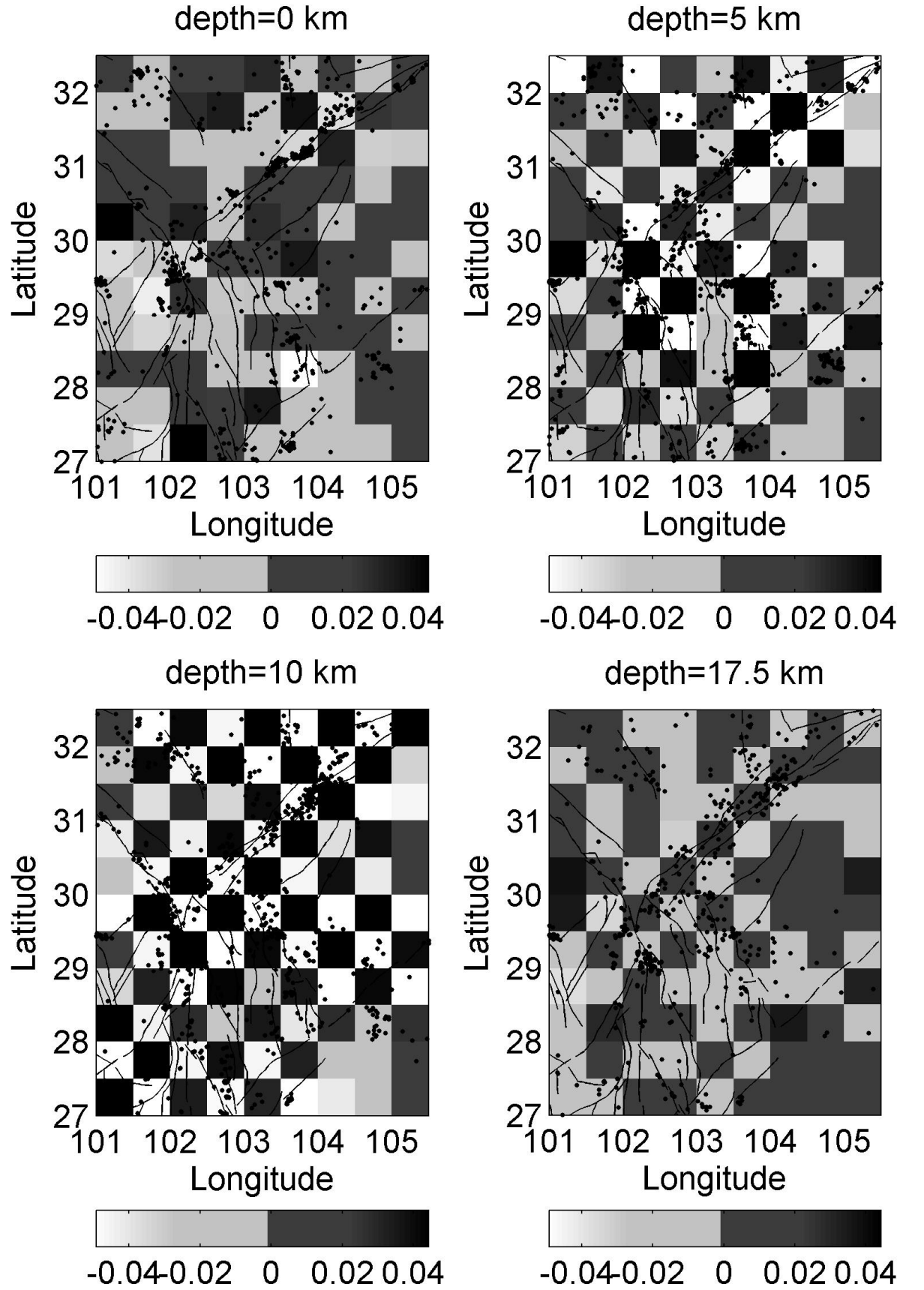

Fig. 8. Horizontal slices of the recovered Vp/Vs checkerboard model. 

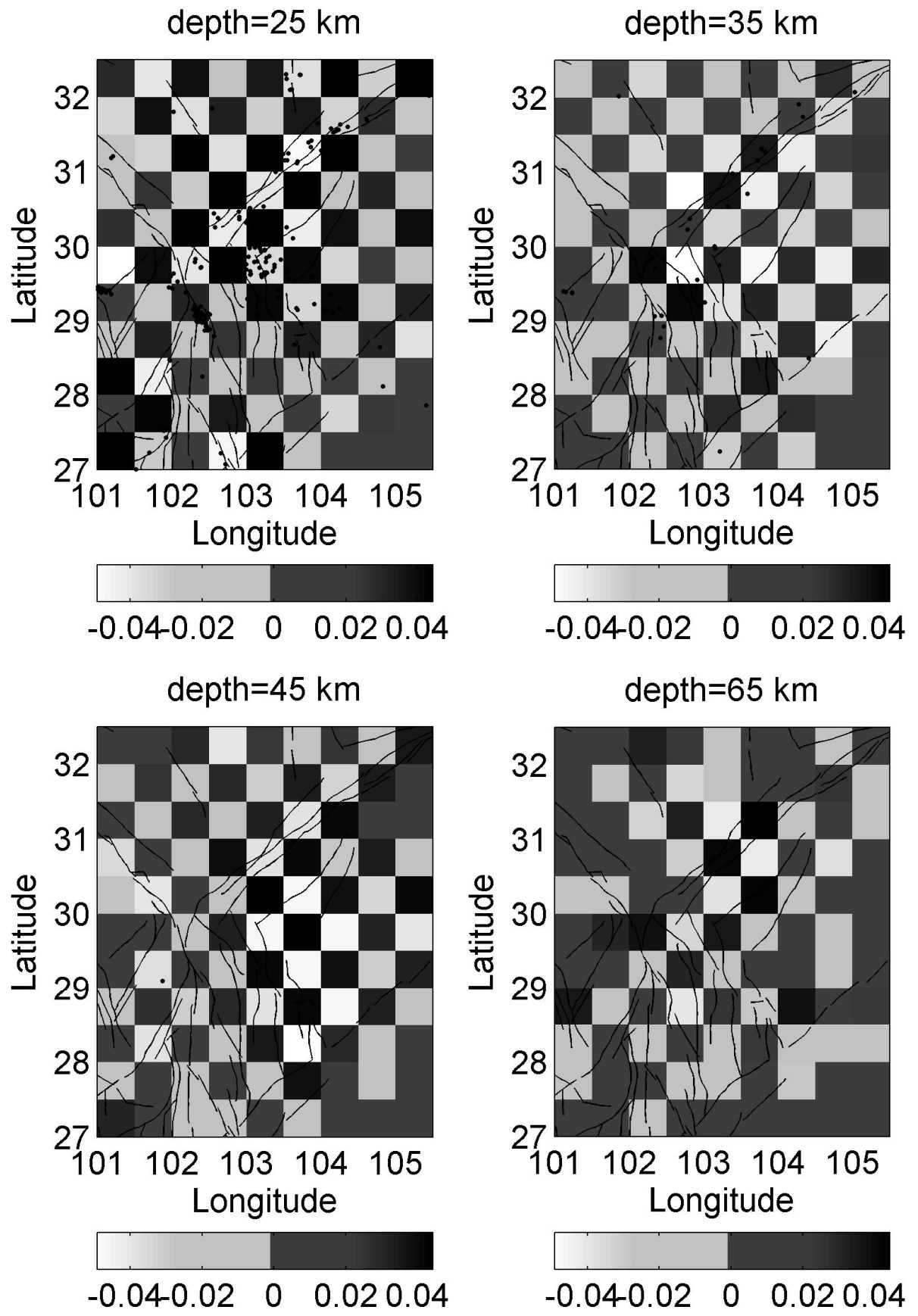

Fig. 8. (Continued) 


\section{Results and discussion}

Figure 9 shows the horizontal slices of the Vp, Vs and Vp/Vs models at depths of $0,5,10$, 17.5, 25, 35, 45 and $65 \mathrm{~km}$. Figures 10, 11 and 12 show the cross sections of the $\mathrm{Vp}$ perturbations, Vs perturbations and $\mathrm{Vp} / \mathrm{Vs}$ model at latitudes of $28^{\circ}, 29^{\circ}, 30^{\circ}, 31^{\circ}$ and $32^{\circ}$, respectively. $\mathrm{Vp}$ and $\mathrm{Vs}$ perturbations are with respect to the $1 \mathrm{D} \mathrm{Vp}$ and $\mathrm{Vs}$ models averaged from the 3D models (Figure 5). Compared to previous tomography studies in the Sichuan region, to our knowledge this is the first time that the $\mathrm{Vp} / \mathrm{Vs}$ model is directly determined from the S-P arrival times instead of being derived from the Vp and Vs models. Pei et al. (2010) used the same methodology of Zhang et al. (2009a, b) to solve for the Vp, Vs and $\mathrm{Vp} / \mathrm{Vs}$ models around the Longmenshan Fault, but the depth extent of the model is only down to $30 \mathrm{~km}$.

At shallow depths (0-5 km), our tomographic velocity models are consistent with the local geology. The Sichuan Basin is clearly imaged as a low velocity region with high $\mathrm{Vp} / \mathrm{Vs}$ ratios (>1.9). The basin is mainly composed of Tertiary, Quaternary to Mesozoic sediments derived from uplift resulting from the collision. Outside the Sichuan Basin, velocities are generally higher and the $\mathrm{Vp} / \mathrm{Vs}$ ratio is lower than 1.7, mainly corresponding to the Songpan-Ganze Terrane. One low velocity zone (low Vp and Vs and high Vp/Vs) in the Sichuan Basin is located between latitudes $31^{\circ}$ to $32^{\circ}$ and longitudes $104^{\circ}$ to $105^{\circ}$, extending all the way from the surface down to the depth of a depth of $25 \mathrm{~km}$. Although this low velocity zone is located around the model edge, the checkerboard resolution tests showed this area has good resolution. Previous tomography studies also identified this low velocity anomaly (Wang et al., 2009).

At deeper depths $(10-25 \mathrm{~km})$, strong velocity variations are present across the region. At 10 $\mathrm{km}$ depth, the Longmen Shan Fault (LMSF) separates a higher velocity region to the northwest from lower velocities to the southeast. At $17.5 \mathrm{~km}$ depth, the velocity contrast is still clear north of latitude $\sim 30.5^{\circ}$, especially for Vs, indicating the LMSF may penetrate at least down to $\sim 18 \mathrm{~km}$. The Longquan anticline separates a relatively lower velocity region to the west and a higher velocity to the east at depths 10 and $17.5 \mathrm{~km}$.

In the Songpan-Ganze Terrane, there are scattered low velocity regions bounded by high velocity bodies in the depth slices of $10 \mathrm{~km}$ and $17.5 \mathrm{~km}$. Especially at $10 \mathrm{~km}$, the velocity pattern resembles the deformation block model found by modeling the GPS data by Shen et al. (2005). The low velocity anomalies generally follow the derived sub-block boundaries. For example, the Songpan-Xihe deformation zone separating the Ahba block to the northwest and the Longmen Shan block to the southeast corresponds to a broad low velocity zone. The Yajiang block bounded by the Xianshuihe Fault, Lijiang Fault, and Litang Fault corresponds to a high velocity body, whereas these faults fall in low velocity zones. The Central Yunnan block bounded by the Anninghe Fault, Zemuhe Fault and Lijiang Fault is also associated with a high velocity body with relatively low velocities around it. The correspondence between low velocity zones and block boundaries indicates that the blocks themselves are strong and are surrounded by relatively weak zones, where deformation mainly occurs. At a depth of $17.5 \mathrm{~km}$, there is a strong low $\mathrm{Vp}$ and $\mathrm{Vs}$ anomaly around latitude $30^{\circ}$ and longitude of $102^{\circ}$, where the Longmen Shan Fault, the Xianshuihe Fault and the Anninghe Fault intersect. This low velocity body corresponds to a normal $\mathrm{Vp} / \mathrm{Vs}$ value of 1.7. Nakajima et al. (2001) also found similar low Vp, low Vs and average to low Vp/Vs patterns in the upper crust of the Japan Island, which they interpreted as being due to the presence of fluids. 

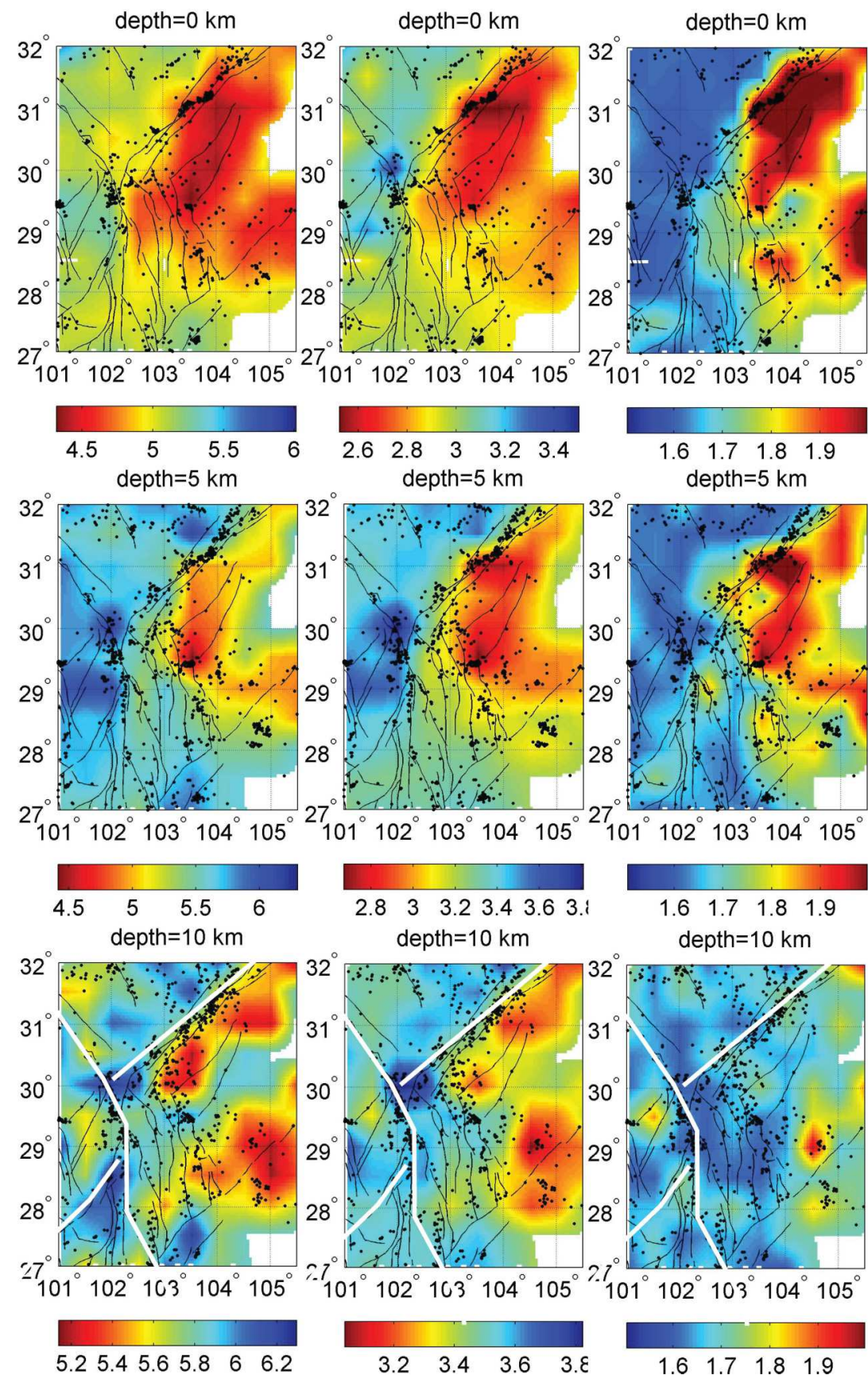

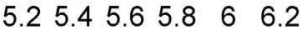

$\begin{array}{llll}3.2 & 3.4 & 3.6 & 3 . \varepsilon\end{array}$

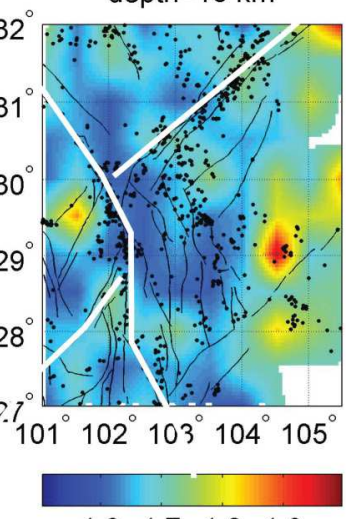

$\begin{array}{llll}1.6 & 1.7 & 1.8 & 1.9\end{array}$

Fig. 9. Horizontal slices of the Vp, Vs and Vp/Vs models at depths 0 to $65 \mathrm{~km}$. 
Seismic Imaging of Microblocks and Weak Zones
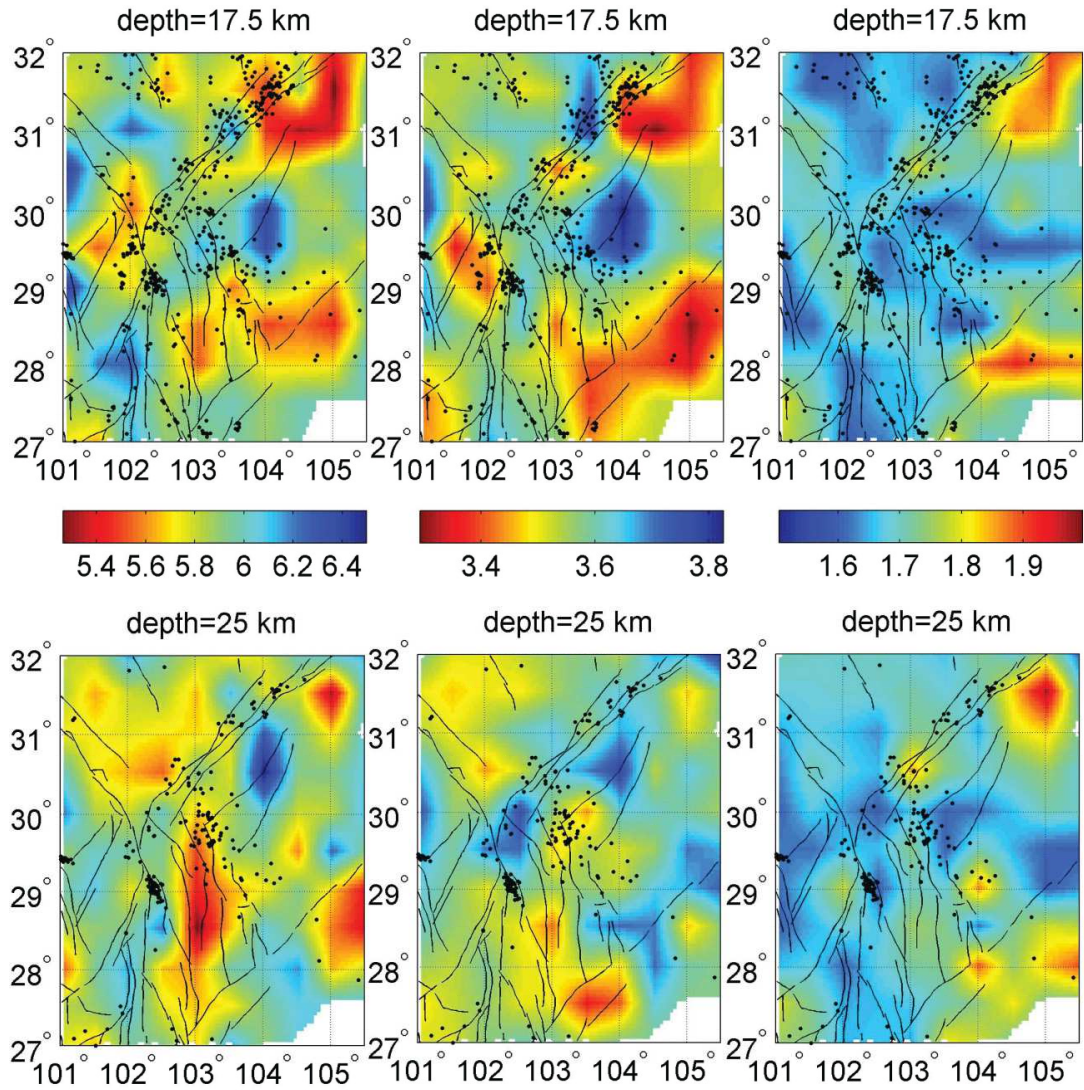

$5.65 .8 \quad 6 \quad 6.26 .46 .6$
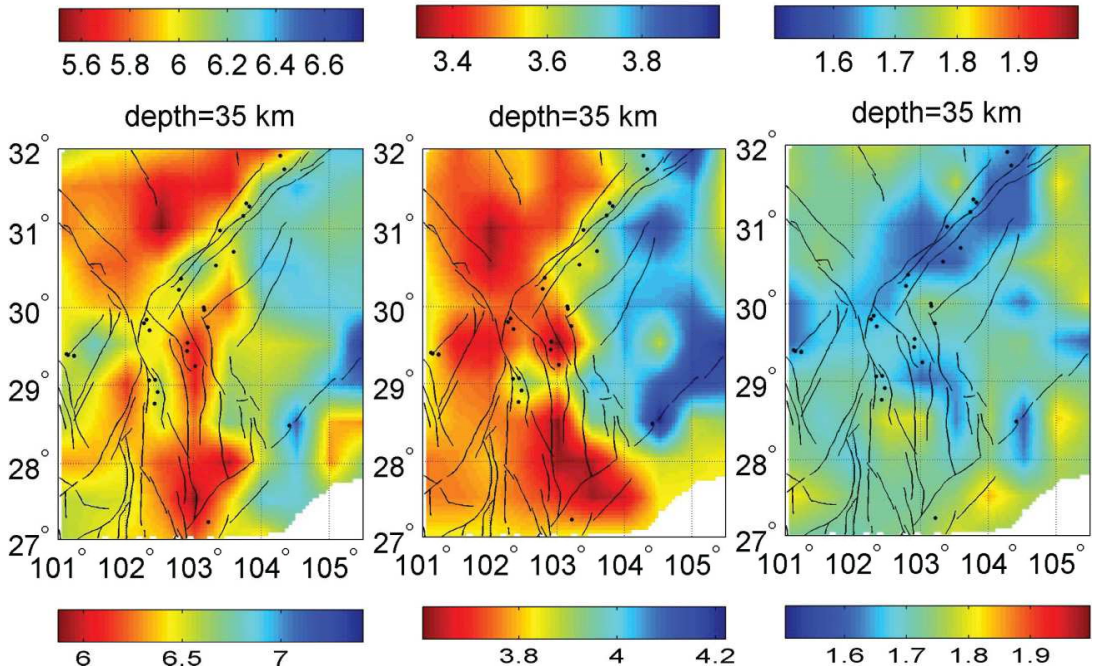

Fig. 9. (Continued) 

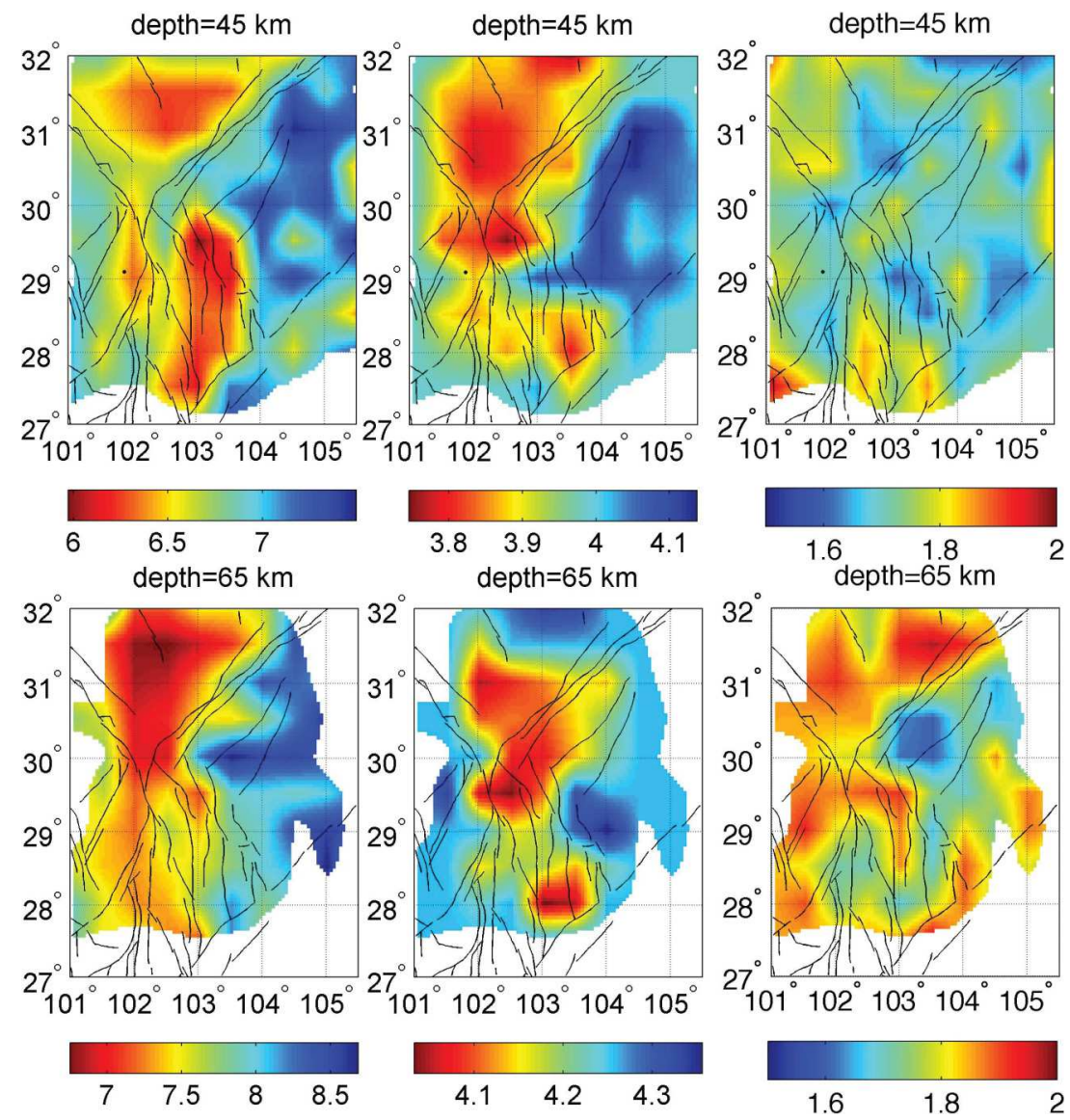

Fig. 9. (Continued) 


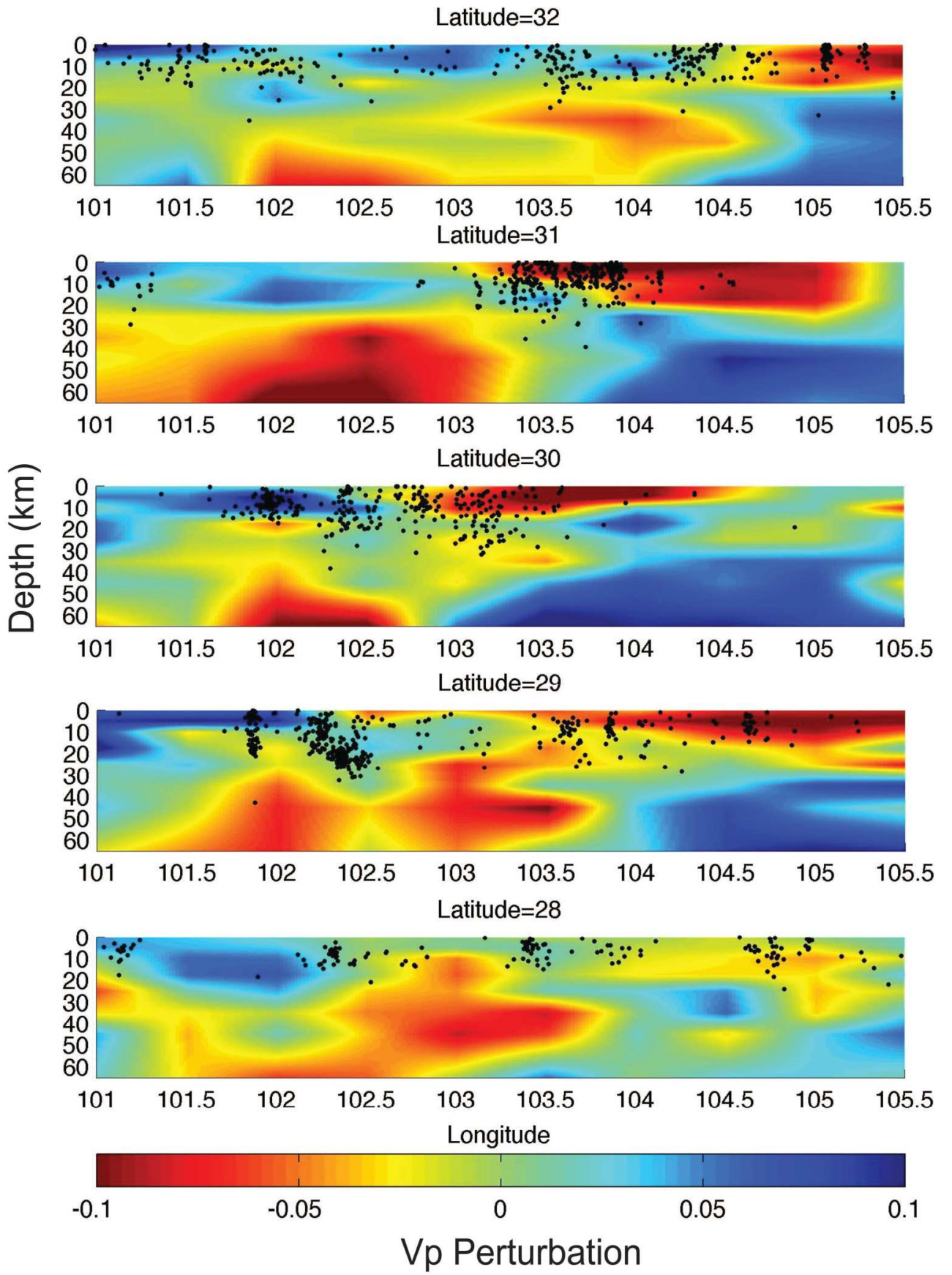

Fig. 10. Cross sections of the Vp perturbation model at latitudes 28, 29, 30, 31, and 32. 


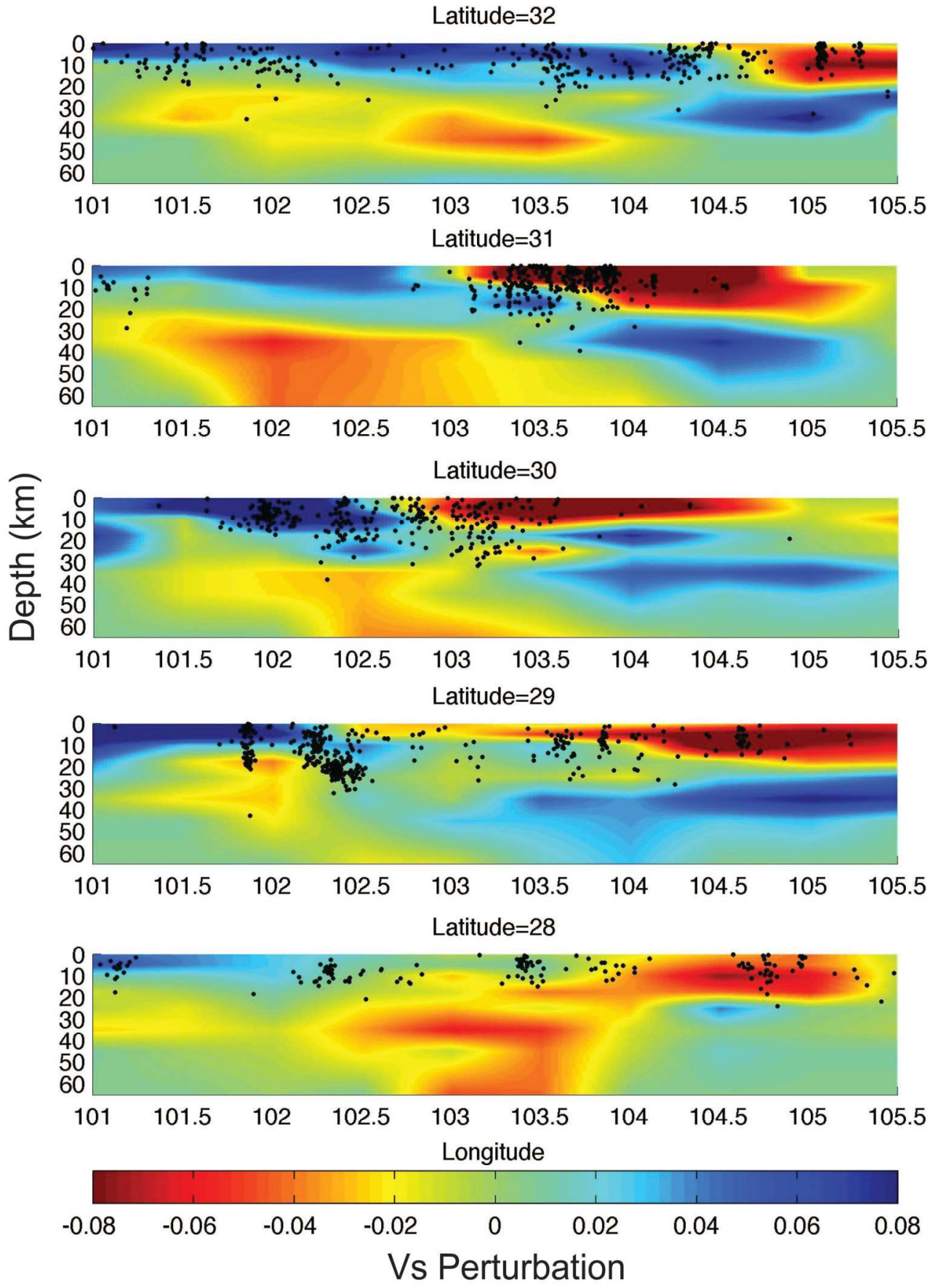

Fig. 11. Cross sections of the Vs perturbation model at latitudes 28, 29, 30, 31, and 32. 


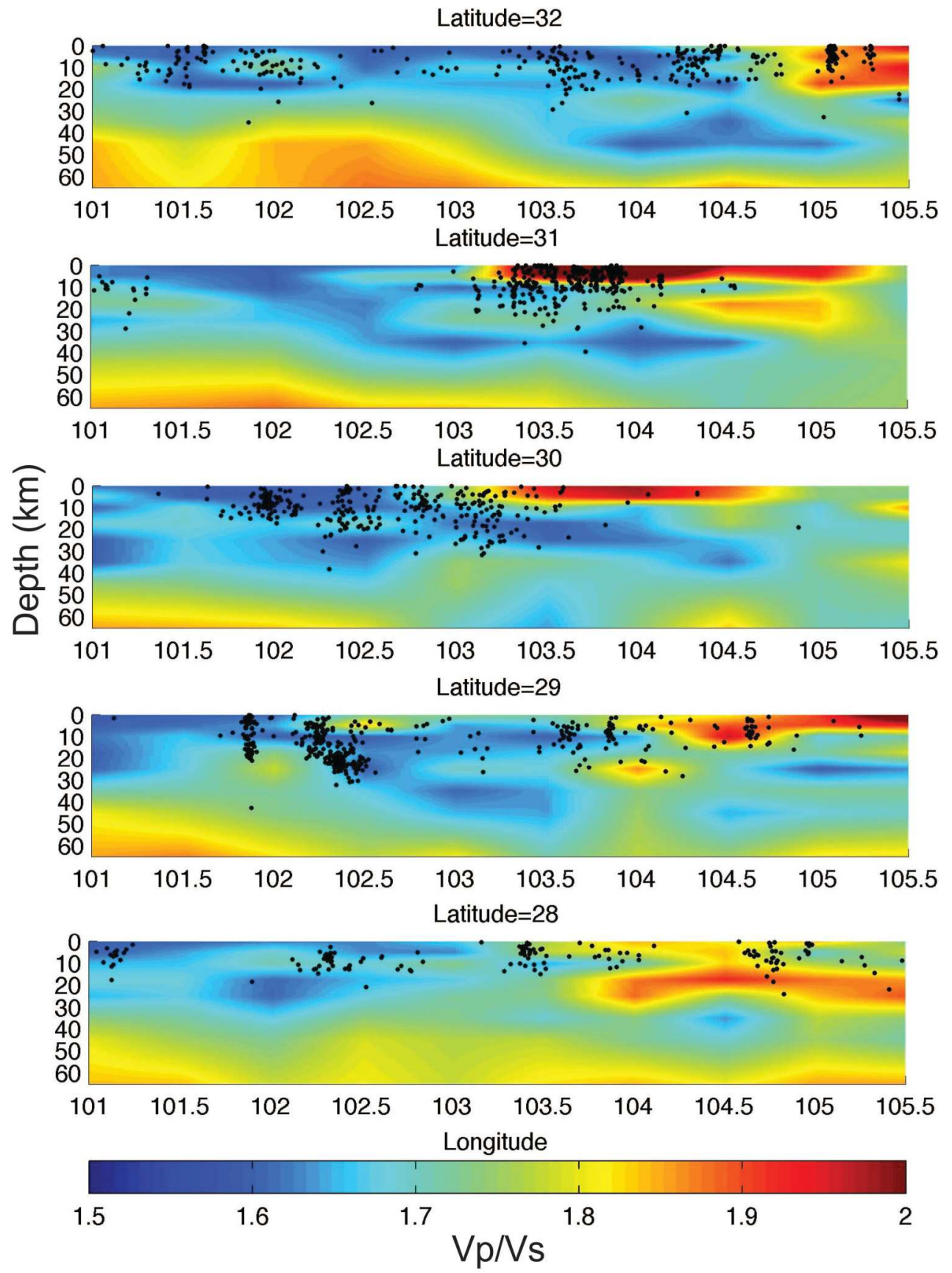

Fig. 12. Cross sections of the Vp/Vs model at latitudes 28, 29, 30, 31, and 32. 
Starting from the depth slice of $25 \mathrm{~km}$ and down to $65 \mathrm{~km}$, we see widespread low velocity zones outside the Sichuan Basin, which itself generally corresponds to a high velocity anomaly. These low velocity zones are not uniformly distributed but vary in amplitude and they are mostly connected to each other. Previous surface wave and body wave tomography studies also found crustal low velocity zones in this region and interpreted them as weak zones for possible channel flow (e.g. Yao et al., 2008, 2010; Wang et al., 2009). However, it is not clear how these low velocity zones are distributed. Are they bounded by the local structures such as faults, which may interrupt or deflect flow? From the Vp model, it is clear that the low velocity zones may be bounded by faults. For example, at depths of $25 \mathrm{~km}$ and $45 \mathrm{~km}$, there is a low velocity zone clearly bounded by the Longmen Shan Fault and Xianshuihe Fault. This low velocity zone dips towards the south and is bounded by the Lijiang Fault and Zemuhe Fault. Another low velocity zone follows the Daliangshan Fault zone from a depth of $25 \mathrm{~km}$ to $65 \mathrm{~km}$. The two low velocity zones seem not to be connected at a depth of $25 \mathrm{~km}$ and are connected at greater depths. Compared to the Vp model, the Vs model does not show such patterns as clearly. This could be due to larger data errors in the $S$ arrival times and relatively poorer Vs model resolution.

From cross sections of $\mathrm{Vp}$ and $\mathrm{Vs}$ perturbations at different latitudes (Figures 10 and 11), we see low velocity anomalies below $\sim 20 \mathrm{~km}$ depth underneath the Songpan-Ganze block. In comparison, the region beneath the Sichuan basin is shown as a high velocity body. For example, in the cross section of latitude $30^{\circ}$, there is an evident low velocity layer in both $\mathrm{Vp}$ and Vs around $20 \mathrm{~km}$ depth from longitude $101.5^{\circ}$ to $102.5^{\circ}$. This low velocity layer was previously detected from a deep seismic sounding profile and by receiver function analysis (Wang et al., 2008) along latitude $30^{\circ}$. A magnetotelluric (MT) survey between longitudes $102^{\circ}$ to $104^{\circ}$ and slightly to the north of latitude $29^{\circ}$ also showed a low resistivity layer around $20 \mathrm{~km}$ depth (Zhao et al., 2008). This low resistivity layer is associated with low Vp, low Vs and high Vp/Vs (Figure 12). Receiver function analysis at station MC09 (latitude $29^{\circ}$ and longitude $102.8^{\circ}$ ) also showed a low Vs layer in the crust associated with a high $\mathrm{Vp} / \mathrm{Vs}$ ratio (Xu et al., 2007).

Because of high regional surface heat flow values (Hu et al., 2000), the low Vp and Vs anomalies in the eastern Tibetan Plateau have been suggested by many researchers to be due to elevated temperatures or partial melt (e.g. Yao et al., 2008). However, the recent receiver function analysis by Robert et al. (2010) found low Vp/Vs (=1.69) beneath the Songpan-Ganze terrane, which is lower than the mean value for continental areas (Zandt and Ammon, 1995). This observation led them to dispute the existence of a thick and extensive zone of partial melt in the crust of the Songpan-Ganze terrane. In contrast, Wang et al. (2008) showed high Vp/Vs (or Poisson ratio) perturbations and $\mathrm{Xu}$ and Song (2010) showed high Poisson ratios in the middle and lower crust of the Songpan-Ganze terrane. Both of their models are obtained by directly dividing Vp by Vs. In comparison, our Vp/Vs model is obtained by directly inverting absolute and differential S-P times and thus is more reliable. Above $\sim 35 \mathrm{~km}$, most of the Songpan-Ganze terrane has a $\mathrm{Vp} / \mathrm{Vs}$ value of $\sim 1.6$. Below $\sim 35 \mathrm{~km}$, the $\mathrm{Vp} / \mathrm{Vs}$ value starts to increase and reaches up to $\sim 1.85$. By averaging from 0 to $60 \mathrm{~km}$, the $\mathrm{Vp} / \mathrm{Vs}$ value from our study is close to what Robert et al. (2008) found from the receiver function analysis. Although low velocity anomalies start from $\sim 20 \mathrm{~km}$ depth in the crust of the eastern Tibetan Plateau, partial melt may not exist until 35 to $40 \mathrm{~km}$ depth where the Vp/Vs ratio is relatively high (Christensen, 1996). In the shallower part, the low velocity anomalies could be caused by the existence of aqueous fluids ( $\mathrm{Li}$ et al., 2003). 
The distribution of aqueous fluids in spheroidal pores can result in low $\mathrm{Vp}$ and Vs anomalies and an average to low $\mathrm{Vp} / \mathrm{Vs}$ anomaly (Takei, 2002). In this study area, the earthquakes are mostly located above $30 \mathrm{~km}$ (Figure 13), supporting the argument that partial melt does not occur above this depth. Most of the earthquakes are located in the region with $\mathrm{Vp}>4.4 \mathrm{~km} / \mathrm{s}$ and $\mathrm{Vs}>2.6 \mathrm{~km}$.
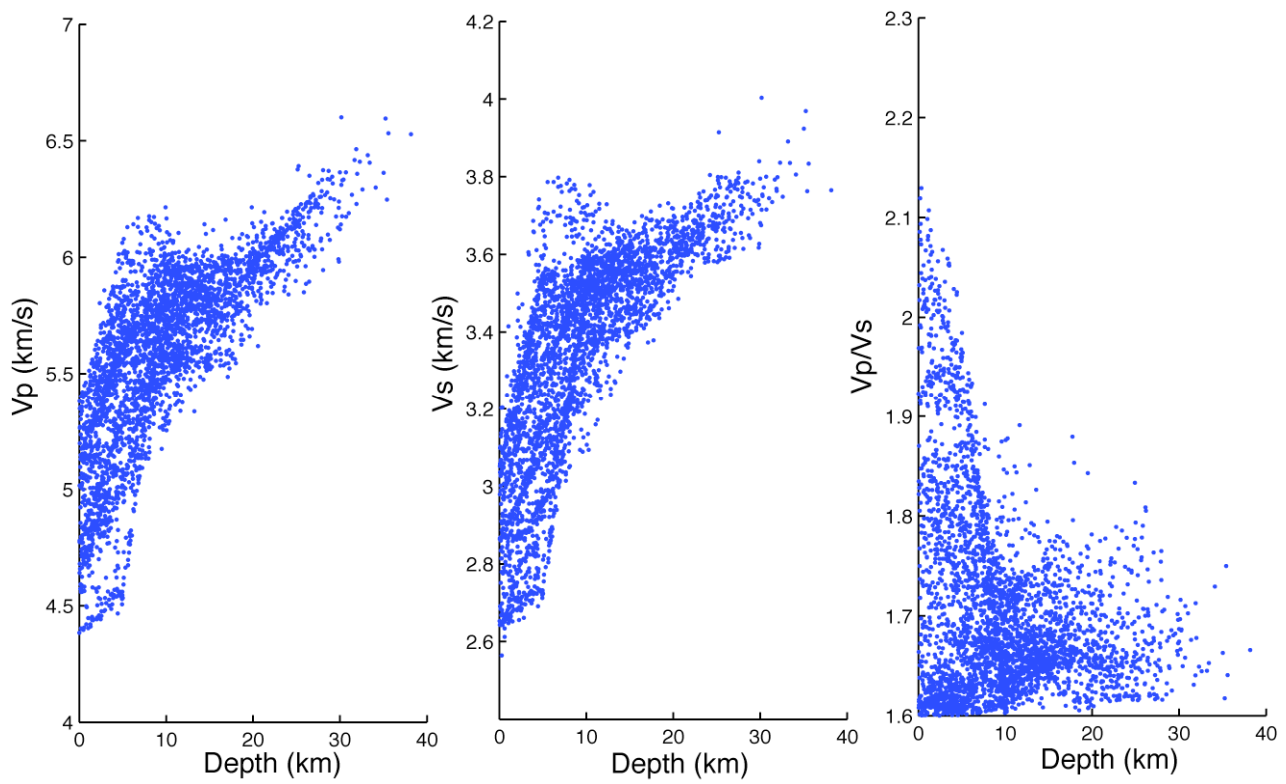

Fig. 13. Scatterplot of hypocenter depth versus Vp, Vs, and Vp/Vs at the hypocenter.

Laboratory experiments show that even a small percentage of melt dramatically reduces the viscosity of rock and it essentially loses its solid nature and behaves like fluid when the melt content reaches $20 \%$ to $55 \%$ (Kohlstedt and Zimmerman, 1996). A rock containing a fluid content greater than $5 \%$ is 10 times weaker than the surrounding material with the same composition (Rosenberg and Handy, 2005). An MT survey through latitude $30^{\circ}$ showed a strong low resistivity anomaly below $\sim 30 \mathrm{~km}$ depth, which may contain $5 \%$ to $20 \%$ of fluid content (Bai et al., 2010). The low velocity layer in the shallower part of the crust (such as depth $17.5 \mathrm{~km}$ ) may play a role of decoupling the upper crust from the mid- and lower crust and the low velocity layer in the lower crust may decouple the crust from the upper mantle. If both low velocity layers exist, they can act as upper and lower sliding planes for the crustal materials to move eastward from the Tibetan Plateau (Teng et al., 2008). Jamieson et al. (2006) found that simply adding a weakened layer in the upper crust to a channel-flow model allowed the model to reproduce several geological observations. Our tomography results support the existence of low velocity zones in the shallower part of the crust. 
The 2008 Wenchuan Ms 8.0 earthquake occurred at latitude $31^{\circ}$ and longitude $103.4^{\circ}$, where there is a high velocity body seen in the $17.5 \mathrm{~km}$ and $25 \mathrm{~km}$ depth slices. This high velocity body may act as a local barrier to the channel flow so that it cannot flow to the east and north. As a result, the strain was continuously built up around the corner and the high velocity body acted as an asperity for the main shock. From a local-scale seismic tomography study around the Longmen Shan Fault using aftershocks of the 2008 Wenchuan earthquake, Pei et al. (2010) found two high velocity bodies around Wenchuan and Beichuan, associated with two large slip patches there. These two high velocity bodies act as asperities for the strain to accumulate and lead to large slip during earthquakes. These two high velocity bodies can also be identified in the depth slice of $17.5 \mathrm{~km}$. There exists a relatively low velocity zone between two high velocity bodies along the Longmen Shan fault, where the aftershocks are relatively sparse (Pei et al., 2010).

\section{Conclusions}

New three-dimensional velocity models including $\mathrm{Vp}, \mathrm{Vs}$ and $\mathrm{Vp} / \mathrm{Vs}$ for the southeastern margin of the Tibetan Plateau covering most of Sichuan, China, provide new insights into the geodynamics of the region. The tectonic subblocks found by modeling the GPS data (Shen et al., 2005) are associated with high velocity (or strong) bodies, surrounded by low velocity (or weak) regions. Widespread low velocity zones are found below $\sim 20 \mathrm{~km}$ depth in the crust with a complicated spatial distribution. At some depths, the low velocity zones are clearly bounded by faults. Aqueous fluids may exist in the mid-crust above $\sim 35 \mathrm{~km}$ depth where the $\mathrm{Vp} / \mathrm{Vs}$ values are low to average. Partial melt may only exist in the deeper part where the $\mathrm{Vp} / \mathrm{Vs}$ values are high. The existence of aqueous fluids and/or partial melt can significantly reduce the strength of rock and allow the channel flow in the crust to occur beneath the southeaster Tibetan Plateau. The 2008 Wenchuan Ms 8.0 earthquake likely resulted from the strain accumulation around the high velocity region near the main shock when the channel flow was obstructed there.

\section{Acknowledgements}

The research presented here was supported by the Chinese government's executive program for exploring the deep interior beneath the Chinese continent (SinoProbe-02). The work was also supported by the Air Force Research Laboratory under contract number FA8718-05-C-0016, and by the Department of Energy under contract number DE-FC5206NA27325 and under grant number DE-FG3608GO18190.

\section{Appendix}

In this appendix, we give details of "edge" and "face" stencils used in the spherical finitedifference travel time calculation method.

\section{1. "Edge" Stencils}

In this stencil (or Scheme B in Vidale (1990)), 3 previously known nodes and one new node are used to compute an unknown time. Typically this occurs on the edges of new faces. All possible stencils are shown in Figure A1.

Using the above stencils, all the derivatives are: 


\section{$\mathrm{dt} / \mathrm{dr}$}

T-N $\left[\left(t_{4}-t_{1}\right)+\left(t_{5}-t_{2}\right)\right] / 2 h$

T-S $\left[\left(t_{4}-t_{1}\right)+\left(t_{5}-t_{2}\right)\right] / 2 h$

T-E $\quad\left[\left(t_{4}-t_{1}\right)+\left(t_{5}-t_{2}\right)\right] / 2 h$

T-W $\left[\left(t_{4}-t_{1}\right)+\left(t_{5}-t_{2}\right)\right] / 2 h$

B-N $\left[\left(t_{1}-t_{4}\right)+\left(t_{2}-t_{5}\right)\right] / 2 h$

B-S $\quad\left[\left(t_{1}-t_{4}\right)+\left(t_{2}-t_{5}\right)\right] / 2 h$

B-E $\quad\left[\left(t_{1}-t_{4}\right)+\left(t_{2}-t_{5}\right)\right] / 2 h$

B-W $\quad\left[\left(t_{1}-t_{4}\right)+\left(t_{2}-t_{5}\right)\right] / 2 h$

W-T $\quad\left[\left(t_{2}-t_{1}\right)+\left(t_{5}-t_{4}\right)\right] / 2 h$

$W-B \quad\left[\left(t_{1}-t_{2}\right)+\left(t_{4}-t_{5}\right)\right] / 2 h$

$W-N \quad\left(t_{0}-t_{3}\right) / 2 h$

W-S $\quad\left(t_{3}-t_{0}\right) / 2 h$

E-T $\quad\left[\left(t_{2}-t_{1}\right)+\left(t_{5}-t_{4}\right)\right] / 2 h$

E-B $\quad\left[\left(t_{1}-t_{2}\right)+\left(t_{4}-t_{5}\right)\right] / 2 h$

E-N $\quad\left(t_{3}-t_{0}\right) / 2 h$

E-S $\quad\left(t_{0}-t_{3}\right) / 2 h$

$N-T \quad\left[\left(t_{2}-t_{1}\right)+\left(t_{5}-t_{4}\right)\right] / 2 h$

$N-B \quad\left[\left(t_{1}-t_{2}\right)+\left(t_{4}-t_{5}\right)\right] / 2 h$

$\mathrm{N}-\mathrm{W} \quad\left(\mathrm{t}_{3}-\mathrm{t}_{0}\right) / 2 \mathrm{~h}$

$\mathrm{N}-\mathrm{E} \quad\left(\mathrm{t}_{0}-\mathrm{t}_{3}\right) / 2 \mathrm{~h}$

S-T $\quad\left[\left(t_{2}-t_{1}\right)+\left(t_{5}-t_{4}\right)\right] / 2 h$

S-B $\quad\left[\left(t_{1}-t_{2}\right)+\left(t_{4}-t_{5}\right)\right] / 2 h$

S-W $\quad\left(t_{0}-t_{3}\right) / 2 h$

S-E $\quad\left(t_{3}-t_{0}\right) / 2 h$
$1 / \mathrm{rdt} / \mathrm{d} \theta$

$\left[\left(t_{4}-t_{5}\right) / r_{2}+\left(t_{1}-t_{2}\right) / r_{1}\right] / 2 \Theta$

$\left[\left(\mathrm{t}_{5}-\mathrm{t}_{4}\right) / \mathrm{r}_{2}+\left(\mathrm{t}_{2}-\mathrm{t}_{1}\right) / \mathrm{r}_{1}\right] / 2 \Theta$

$\left[\left(\mathrm{t}_{0}-\mathrm{t}_{3}\right) / \mathrm{r}_{1}\right] / 2 \Theta$

$\left[\left(\mathrm{t}_{3}-\mathrm{t}_{0}\right) / \mathrm{r}_{1}\right] / 2 \Theta$

$\left[\left(t_{4}-t_{5}\right) / r_{2}+\left(t_{1}-t_{2}\right) / r_{1}\right] / 2 \Theta$

$\left[\left(\mathrm{t}_{5}-\mathrm{t}_{4}\right) / \mathrm{r}_{2}+\left(\mathrm{t}_{2}-\mathrm{t}_{1}\right) / \mathrm{r}_{1}\right] / 2 \Theta$

$\left[\left(\mathrm{t}_{3}-\mathrm{t}_{0}\right) / \mathrm{r}_{1}\right] / 2 \Theta$

$\left[\left(\mathrm{t}_{0}-\mathrm{t}_{3}\right) / \mathrm{r}_{1}\right] / 2 \Theta$

$\left[\left(\mathrm{t}_{0}-\mathrm{t}_{3}\right) / \mathrm{r}_{1}\right] / 2 \Theta$

$\left[\left(t_{3}-t_{0}\right) / r_{1}\right] / 2 \Theta$

$\left[\left(t_{4}-t_{5}\right)+\left(t_{1}-t_{2}\right)\right] / 2 r_{1} \Theta$

$\left[\left(t_{5}-t_{4}\right)+\left(t_{2}-t_{1}\right)\right] / 2 r_{1} \Theta$

$\left[\left(\mathrm{t}_{3}-\mathrm{t}_{0}\right) / \mathrm{r}_{1}\right] / 2 \Theta$

$\left[\left(\mathrm{t}_{0}-\mathrm{t}_{3}\right) / \mathrm{r}_{1}\right] / 2 \Theta$

$\left[\left(t_{4}-t_{5}\right)+\left(t_{1}-t_{2}\right)\right] / 2 r_{1} \Theta$

$\left[\left(t_{5}-t_{4}\right)+\left(t_{2}-t_{1}\right)\right] / 2 r_{1} \Theta$

$\left[\left(t_{2}-t_{5}\right) / r_{2}+\left(t_{1}-t_{4}\right) / r_{1}\right] / 2 \Theta$

$\left[\left(t_{2}-t_{5}\right) / r_{2}+\left(t_{1}-t_{4}\right) / r_{1}\right] / 2 \Theta$

$\left[\left(t_{2}-t_{5}\right)+\left(t_{1}-t_{4}\right)\right] / 2 r_{1} \Theta$

$\left[\left(t_{2}-t_{5}\right)+\left(t_{1}-t_{4}\right)\right] / 2 r_{1} \Theta$

$\left[\left(t_{5}-t_{2}\right) / r_{2}+\left(t_{4}-t_{1}\right) / r_{1}\right] / 2 \Theta$

$\left[\left(t_{5}-t_{2}\right) / r_{2}+\left(t_{4}-t_{1}\right) / r_{1}\right] / 2 \Theta$

$\left[\left(t_{5}-t_{2}\right)+\left(t_{4}-t_{1}\right)\right] / 2 r_{1} \Theta$

$\left[\left(t_{5}-t_{2}\right)+\left(t_{4}-t_{1}\right)\right] / 2 r_{1} \Theta$
$1 / \mathrm{r} \sin \theta \mathrm{dt} / \mathrm{d} \phi$

$\left[\left(\mathrm{t}_{0}-\mathrm{t}_{3}\right) / \mathrm{r}_{1} \sin \theta\right] / 2 \Phi$

$\left[\left(\mathrm{t}_{3}-\mathrm{t}_{0}\right) / \mathrm{r}_{1} \sin \theta\right] / 2 \Phi$

$\left[\left(\mathrm{t}_{5}-\mathrm{t}_{4}\right) / \mathrm{r}_{2}+\left(\mathrm{t}_{2}-\mathrm{t}_{1}\right) / \mathrm{r}_{1}\right] / 2 \Phi \sin \theta$

$\left[\left(t_{4}-t_{5}\right) / r_{2}+\left(t_{1}-t_{2}\right) / r_{1}\right] / 2 \Phi \sin \theta$

$\left[\left(t_{3}-t_{0}\right) / r_{1} \sin \theta\right] / 2 \Phi$

$\left[\left(\mathrm{t}_{0}-\mathrm{t}_{3}\right) / \mathrm{r}_{1} \sin \theta\right] / 2 \Phi$

$\left[\left(\mathrm{t}_{5}-\mathrm{t}_{4}\right) / \mathrm{r}_{2}+\left(\mathrm{t}_{2}-\mathrm{t}_{1}\right) / \mathrm{r}_{1}\right] / 2 \Phi \sin \theta$

$\left[\left(t_{4}-t_{5}\right) / r_{2}+\left(t_{1}-t_{2}\right) / r_{1}\right] / 2 \Phi \sin \theta$

$\left[\left(t_{2}-t_{5}\right) / r_{2}+\left(t_{1}-t_{4}\right) / r_{1}\right] / 2 \Phi \sin \theta$

$\left[\left(t_{2}-t_{5}\right) / r_{2}+\left(t_{1}-t_{4}\right) / r_{1}\right] / 2 \Phi \sin \theta$

$\left[\left(\mathrm{t}_{1}-\mathrm{t}_{4}\right) / \sin \theta_{1}+\left(\mathrm{t}_{2}-\mathrm{t}_{5}\right) / \sin \theta_{2}\right] / 2 \mathrm{r}_{1} \Phi$

$\left[\left(\mathrm{t}_{1}-\mathrm{t}_{4}\right) / \sin \theta_{1}+\left(\mathrm{t}_{2}-\mathrm{t}_{5}\right) / \sin \theta_{2}\right] / 2 \mathrm{r}_{1} \Phi$

$\left[\left(t_{5}-t_{2}\right) / r_{2}+\left(t_{4}-t_{1}\right) / r_{1}\right] / 2 \Phi \sin \theta$

$\left[\left(\mathrm{t}_{5}-\mathrm{t}_{2}\right) / \mathrm{r}_{2}+\left(\mathrm{t}_{4}-\mathrm{t}_{1}\right) / \mathrm{r}_{1}\right] / 2 \Phi \sin \theta$

$\left[\left(\mathrm{t}_{4}-\mathrm{t}_{1}\right) / \sin \theta_{1}+\left(\mathrm{t}_{5}-\mathrm{t}_{2}\right) / \sin \theta_{2}\right] / 2 \mathrm{r}_{1} \Phi$

$\left[\left(\mathrm{t}_{4}-\mathrm{t}_{1}\right) / \sin \theta_{1}+\left(\mathrm{t}_{5}-\mathrm{t}_{2}\right) / \sin \theta_{2}\right] / 2 \mathrm{r}_{1} \Phi$

$\left(t_{3}-t_{0}\right) / 2 r_{1} \sin \theta \Phi$

$\left(\mathrm{t}_{0}-\mathrm{t}_{3}\right) / 2 \mathrm{r}_{1} \sin \theta \Phi$

$\left[\left(\mathrm{t}_{1}-\mathrm{t}_{2}\right) / \sin \theta_{1}+\left(\mathrm{t}_{4}-\mathrm{t}_{5}\right) / \sin \theta_{2}\right] / 2 \mathrm{r}_{1} \Phi$

$\left[\left(\mathrm{t}_{2}-\mathrm{t}_{1}\right) / \sin \theta_{1}+\left(\mathrm{t}_{5}-\mathrm{t}_{4}\right) / \sin \theta_{2}\right] / 2 \mathrm{r}_{1} \Phi$

$\left(\mathrm{t}_{0}-\mathrm{t}_{3}\right) / 2 \mathrm{r}_{1} \sin \theta \Phi$

$\left(t_{3}-t_{0}\right) / 2 r_{1} \sin \theta \Phi$

$\left[\left(t_{1}-t_{2}\right) / \sin \theta_{1}+\left(t_{4}-t_{5}\right) / \sin \theta_{2}\right] / 2 r_{1} \Phi$

$\left[\left(\mathrm{t}_{2}-\mathrm{t}_{1}\right) / \sin \theta_{1}+\left(\mathrm{t}_{5}-\mathrm{t}_{4}\right) / \sin \theta_{2}\right] / 2 \mathrm{r}_{1} \Phi$

Note that for each case:

$\mathrm{T}-\mathrm{N}=+-(\mathrm{T}-\mathrm{S})=+-(\mathrm{B}-\mathrm{N})=+-(\mathrm{B}-\mathrm{S})$

$\mathrm{T}-\mathrm{E}=+-(\mathrm{T}-\mathrm{W})=+-(\mathrm{B}-\mathrm{E})=+-(\mathrm{B}-\mathrm{W})$

$\mathrm{W}-\mathrm{T}=+-(\mathrm{W}-\mathrm{B})=+-(\mathrm{E}-\mathrm{T})=+-(\mathrm{E}-\mathrm{B})$

$\mathrm{W}-\mathrm{N}=+-(\mathrm{W}-\mathrm{S})=+-(\mathrm{E}-\mathrm{N})=+-(\mathrm{E}-\mathrm{S})$

$\mathrm{N}-\mathrm{T}=+-(\mathrm{N}-\mathrm{B})=+-(\mathrm{S}-\mathrm{T})=+-(\mathrm{S}-\mathrm{B})$

$\mathrm{N}-\mathrm{W}=+-(\mathrm{S}-\mathrm{W})=+-(\mathrm{N}-\mathrm{E})=+-(\mathrm{S}-\mathrm{E})$

So, because we square derivatives, we need only concern ourselves with expressions for 6 cases.

$\begin{array}{llll} & d t / d r & 1 / r d t / d \theta & 1 / r \sin \theta d t / d \phi \\ \text { T-N } & {\left[\left(t_{4}-t_{1}\right)+\left(t_{5}-t_{2}\right)\right] / 2 h} & {\left[\left(t_{4}-t_{5}\right) / r_{2}+\left(t_{1}-t_{2}\right) / r_{1}\right] / 2 \Theta} & {\left[\left(t_{0}-t_{3}\right) / r_{1} \sin \theta\right] / 2 \Phi} \\ \text { T-W } & {\left[\left(t_{4}-t_{1}\right)+\left(t_{5}-t_{2}\right)\right] / 2 h} & {\left[\left(t_{3}-t_{0}\right) / r_{1}\right] / 2 \Theta} & {\left[\left(t_{4}-t_{5}\right) / r_{2}+\left(t_{1}-t_{2}\right) / r_{1}\right] / 2 \Phi \sin \theta} \\ W-T & {\left[\left(t_{2}-t_{1}\right)+\left(t_{5}-t_{4}\right)\right] / 2 h} & {\left[\left(t_{0}-t_{3}\right) / r_{1}\right] / 2 \Theta} & {\left[\left(t_{2}-t_{5}\right) / r_{2}+\left(t_{1}-t_{4}\right) / r_{1}\right] / 2 \Phi \sin \theta} \\ \text { W-N } & \left(t_{0}-t_{3}\right) / 2 h & {\left[\left(t_{4}-t_{5}\right)+\left(t_{1}-t_{2}\right)\right] / 2 r_{1} \Theta} & {\left[\left(t_{1}-t_{4}\right) / \sin \theta_{1}+\left(t_{2}-t_{5}\right) / \sin \theta_{2}\right] / 2 r_{1} \Phi} \\ \text { N-T } & {\left[\left(t_{2}-t_{1}\right)+\left(t_{5}-t_{4}\right)\right] / 2 h} & {\left[\left(t_{2}-t_{5}\right) / r_{2}+\left(t_{1}-t_{4}\right) / r_{1}\right] / 2 \Theta} & \left(t_{3}-t_{0}\right) / 2 r_{1} \sin \theta \Phi \\ \text { N-W } & \left(t_{3}-t_{0}\right) / 2 h & {\left[\left(t_{2}-t_{5}\right)+\left(t_{1}-t_{4}\right)\right] / 2 r_{1} \Theta} & {\left[\left(t_{1}-t_{2}\right) / \sin \theta_{1}+\left(t_{4}-t_{5}\right) / \sin \theta_{2}\right] / 2 r_{1} \Phi}\end{array}$

The general form of the equation is: 
$4 s^{2}=\left[\left(t_{4}-t_{1}\right) / d_{14}+\left(t_{5}-t_{2}\right) / d_{25}\right]^{2}+\left[\left(t_{4}-t_{5}\right) / d_{45}+\left(t_{1}-t_{2}\right) / d_{12}\right]^{2}+\left[\left(t_{0}-t_{3}\right) / d_{01}\right]^{2}$

And we solve for $t_{5}$

$4 \mathrm{~s}^{2}=\left[\left(\mathrm{t}_{4}-\mathrm{t}_{1}\right) / \mathrm{d}_{14}\right]^{2}+\left[\left(\mathrm{t}_{1}-\mathrm{t}_{2}\right) / \mathrm{d}_{12}\right]^{2}+\left[\left(\mathrm{t}_{0}-\mathrm{t}_{3}\right) / \mathrm{d}_{01}\right]^{2}$

$+\left[\left(t_{5}^{2}+t_{2}{ }^{2}-2 t_{2} t_{5}\right) / d_{25}{ }^{2}+2\left(t_{1} t_{2}-t_{1} t_{5}-t_{2} t_{4}+t_{4} t_{5}\right) / d_{14} d_{25}\right]$

$+\left[\left(t_{5}^{2}+t_{4}^{2}-2 t_{4} t_{5}\right) / d_{45^{2}}+2\left(t_{1} t_{4}-t_{1} t_{5}-t_{2} t_{4}+t_{2} t_{5}\right) / d_{12} d_{45}\right]$

Isolating $t_{5}$ :

$4 s^{2}=\left[\left(t_{5}{ }^{2}-2 t_{2} t_{5}\right) / d_{25} 5^{2}+2\left(-t_{1} t_{5}+t_{4} t_{5}\right) / d_{14} d_{25}\right]+\left[\left(t_{5}^{2}-2 t_{4} t_{5}\right) / d_{45}{ }^{2}+2\left(-t_{1} t_{5}+t_{2} t_{5}\right) / d_{12} d_{45}\right]$

$+\left[\left(\mathrm{t}_{4}-\mathrm{t}_{1}\right) / \mathrm{d}_{14}\right]^{2}+\left[\left(\mathrm{t}_{1}-\mathrm{t}_{2}\right) / \mathrm{d}_{12}\right]^{2}+\left[\left(\mathrm{t}_{0}-\mathrm{t}_{3}\right) / \mathrm{d}_{01}\right]^{2}$

$+\left[\left(t_{2}^{2}\right) / d_{25}{ }^{2}+2\left(t_{1} t_{2}-t_{2} t_{4}\right) / d_{14} d_{25}\right]+\left[\left(t_{4}^{2}\right) / d_{45^{2}}+2\left(t_{1} t_{4}-t_{2} t_{4}\right) / d_{12} d_{45}\right]$

$4 s^{2}=t_{5}^{2}\left[1 / d_{25^{2}}+1 / d_{45^{2}}\right]+2 t_{5}\left[\left(-t_{2}\right) / d_{25^{2}}+\left(-t_{1}+t_{4}\right) / d_{14} d_{25}+\left(-t_{4}\right) / d_{45^{2}}+\left(-t_{1}+t_{2}\right) / d_{12} d_{45}\right]$

$+\left[\left(t_{4}-t_{1}\right) / d_{14}\right]^{2}+\left[\left(t_{2}^{2}\right) / d_{25}+2 t_{2}\left(t_{1}-t_{4}\right) / d_{14} d_{25}\right]$

$+\left[\left(t_{2}-t_{1}\right) / d_{12}\right]^{2}+\left[\left(t_{4}^{2}\right) / d_{45}+2 t_{4}\left(t_{1}-t_{2}\right) / d_{12} d_{45}\right]+\left[\left(t_{0}-t_{3}\right) / d_{01}\right]^{2}$

$4 \mathrm{~s}^{2}=\mathrm{t}_{5}{ }^{2}\left[1 / \mathrm{d}_{25}{ }^{2}+1 / \mathrm{d}_{\left.45^{2}\right]}\right]+2 \mathrm{t}_{5}\left[\left(-\mathrm{t}_{2}\right) / \mathrm{d}_{25^{2}}+\left(\mathrm{t}_{4}-\mathrm{t}_{1}\right) / \mathrm{d}_{14} \mathrm{~d}_{25}+\left(-\mathrm{t}_{4}\right) / \mathrm{d}_{45^{2}}+\left(\mathrm{t}_{2}-\mathrm{t}_{1}\right) / \mathrm{d}_{12} \mathrm{~d}_{45}\right]$

$+\left[\left(\mathrm{t}_{4}-\mathrm{t}_{1}\right) / \mathrm{d}_{14}-\mathrm{t}_{2} / \mathrm{d}_{25}\right]^{2}+\left[\left(\mathrm{t}_{2}-\mathrm{t}_{1}\right) / \mathrm{d}_{12}-\mathrm{t}_{4} / \mathrm{d}_{45}\right]^{2}+\left[\left(\mathrm{t}_{0}-\mathrm{t}_{3}\right) / \mathrm{d}_{01}\right]^{2}$

$4 s^{2}=t_{5}{ }^{2}\left[1 / d_{25}{ }^{2}+1 / d_{45^{2}}\right]+2 t_{5}\left[\left(t_{4}-t_{1}\right) / d_{14} d_{25}+\left(t_{2}-t_{1}\right) / d_{12} d_{45}-t_{2} / d_{25}{ }^{2}-t_{4} / d_{45^{2}}\right]$

$+\left[\left(t_{4}-t_{1}\right) / d_{14}-t_{2} / d_{25}\right]^{2}+\left[\left(t_{2}-t_{1}\right) / d_{12}-t_{4} / d_{45}\right]^{2}+\left[\left(t_{0}-t_{3}\right) / d_{01}\right]^{2}$

$\begin{array}{llllll} & \mathrm{d}_{01} & \mathrm{~d}_{12} & \mathrm{~d}_{14} & \mathrm{~d}_{25} & \mathrm{~d}_{45} \\ \text { TN } & \mathrm{r}_{2} \sin \theta_{2} \Phi & \mathrm{r}_{2} \Theta & \mathrm{h} & \mathrm{h} & \mathrm{r}_{1} \Theta \\ \mathrm{TW} & \mathrm{r}_{2} \Theta & \mathrm{r}_{2} \sin \theta_{1} \Phi & \mathrm{h} & \mathrm{h} & \mathrm{r}_{1} \sin \theta_{1} \Phi \\ \mathrm{NW} & \mathrm{h} & \mathrm{r}_{1} \sin \theta_{2} \Phi & \mathrm{r}_{1} \Theta & \mathrm{r}_{1} \Theta & \mathrm{r}_{1} \sin \theta_{1} \Phi \\ \mathrm{NT} & \mathrm{r}_{2} \sin \theta_{2} \Phi & \mathrm{h} & \mathrm{r}_{2} \Theta & \mathrm{r}_{1} \Theta & \mathrm{h} \\ \mathrm{WN} & \mathrm{h} & \mathrm{r}_{2} \Theta & \mathrm{r}_{1} \sin \theta_{2} \Phi & \mathrm{r}_{1} \sin \theta_{1} \Phi & \mathrm{r}_{2} \Theta \\ \text { WT } & \mathrm{r}_{2} \Theta & \mathrm{h} & \mathrm{r}_{2} \sin \theta_{2} \Phi & \mathrm{r}_{1} \sin \theta_{1} \Phi & \mathrm{h}\end{array}$

In General:

$4 s^{2}=a_{5}{ }^{2}+b t_{5}+c$

with

$\mathrm{a}=1 / \mathrm{d}_{25^{2}}+1 / \mathrm{d}_{45}{ }^{2}$

$\mathrm{b}=2\left[\left(\mathrm{t}_{4}-\mathrm{t}_{1}\right) / \mathrm{d}_{14} \mathrm{~d}_{25}+\left(\mathrm{t}_{2}-\mathrm{t}_{1}\right) / \mathrm{d}_{12} \mathrm{~d}_{45}-\mathrm{t}_{2} / \mathrm{d}_{25^{2}}-\mathrm{t}_{4} / \mathrm{d}_{45^{2}}\right]$

$\left.\mathrm{b}=2\left[\left(\mathrm{t}_{4}-\mathrm{t}_{1}\right) / \mathrm{d}_{14}-\mathrm{t}_{2} / \mathrm{d}_{25}\right] / \mathrm{d}_{25}+\left[\left(\mathrm{t}_{2}-\mathrm{t}_{1}\right) / \mathrm{d}_{12}-\mathrm{t}_{4} / \mathrm{d}_{45}\right] / \mathrm{d}_{45}\right]$

When $\mathrm{d}_{14}=\mathrm{d}_{25}(\mathrm{TN}, \mathrm{TW}, \mathrm{NW})$

$\mathrm{b}=2\left[\left(\mathrm{t}_{4}-\mathrm{t}_{1}-\mathrm{t}_{2}\right) / \mathrm{d}_{25^{2}}+\left(\mathrm{t}_{2}-\mathrm{t}_{1}\right) / \mathrm{d}_{12} \mathrm{~d}_{45}-\mathrm{t}_{4} / \mathrm{d}_{45^{2}}\right]$

When $\mathrm{d}_{12}=\mathrm{d}_{45}(\mathrm{WN}, \mathrm{WT}, \mathrm{NT})$

$\mathrm{b}=2\left[\left(\mathrm{t}_{2}-\mathrm{t}_{1}-\mathrm{t}_{4}\right) / \mathrm{d}_{45^{2}}+\left(\mathrm{t}_{4}-\mathrm{t}_{1}\right) / \mathrm{d}_{14} \mathrm{~d}_{25}-\mathrm{t}_{2} / \mathrm{d}_{25}{ }^{2}\right]$

$c=\left[\left(t_{4}-t_{1}\right) / d_{14}-t_{2} / d_{25}\right]^{2}+\left[\left(t_{2}-t_{1}\right) / d_{12}-t_{4} / d_{45}\right]^{2}+\left[\left(t_{0}-t_{3}\right) / d_{01}\right]^{2}-4 s^{2}$

When $\mathrm{d}_{14}=\mathrm{d}_{25}(\mathrm{TN}, \mathrm{TW}, \mathrm{NW})$

$c=\left[\left(t_{4}-t_{1}-t_{2}\right) / d_{25}\right]^{2}+\left[\left(t_{2}-t_{1}\right) / d_{12}-t_{4} / d_{45}\right]^{2}+\left[\left(t_{0}-t_{3}\right) / d_{01}\right]^{2}-4 s^{2}$ 
When $\mathrm{d}_{12}=\mathrm{d}_{45}(\mathrm{WN}, \mathrm{WT}, \mathrm{NT})$

$c=\left[\left(t_{2}-t_{1}-t_{4}\right) / d_{45}\right]^{2}+\left[\left(t_{4}-t_{1}\right) / d_{14}-t_{2} / d_{25}\right]^{2}+\left[\left(t_{0}-t_{3}\right) / d_{01}\right]^{2}-4 s^{2}$

\section{Face stencils (or Scheme $C$ in Vidale (1990))}

New face stencils solve for point 5 on a new face given 4 points on an existing face. The geometries are shown in Figure A2. Given the geometries shown, the derivatives are:

$\begin{array}{llll} & \mathrm{dt} / \mathrm{dr} & 1 / \mathrm{rdt} / \mathrm{d} \theta & 1 / \mathrm{r} \sin \theta \mathrm{dt} / \mathrm{d} \phi \\ \mathrm{T} & \left(\mathrm{t}_{5}-\mathrm{t}_{2}\right) / \mathrm{h} & \left(\mathrm{t}_{0}-\mathrm{t}_{4}\right) / 2 \mathrm{r}_{1} \Theta & \left(\mathrm{t}_{3}-\mathrm{t}_{1}\right) / 2 \mathrm{r}_{2} \sin \theta_{1} \Phi \\ \mathrm{B} & \left(\mathrm{t}_{2}-\mathrm{t}_{5}\right) / \mathrm{h} & \left(\mathrm{t}_{0}-\mathrm{t}_{4}\right) / 2 \mathrm{r}_{1} \Theta & \left(\mathrm{t}_{1}-\mathrm{t}_{3}\right) / 2 \mathrm{r}_{2} \sin \theta_{1} \Phi \\ \mathrm{N} & \left(\mathrm{t}_{4}-\mathrm{t}_{0}\right) / 2 \mathrm{~h} & \left(\mathrm{t}_{2}-\mathrm{t}_{5}\right) / \mathrm{r}_{1} \Theta & \left(\mathrm{t}_{1}-\mathrm{t}_{3}\right) / 2 \mathrm{r}_{2} \sin \theta_{2} \Phi \\ \mathrm{S} & \left(\mathrm{t}_{4}-\mathrm{t}_{0}\right) / 2 \mathrm{~h} & \left(\mathrm{t}_{5}-\mathrm{t}_{2}\right) / \mathrm{r}_{1} \Theta & \left(\mathrm{t}_{3}-\mathrm{t}_{1}\right) / 2 \mathrm{r}_{1} \sin \theta_{2} \Phi \\ \mathrm{W} & \left(\mathrm{t}_{3}-\mathrm{t}_{1}\right) / 2 \mathrm{~h} & \left(\mathrm{t}_{0}-\mathrm{t}_{4}\right) / 2 \mathrm{r}_{1} \Theta & \left(\mathrm{t}_{2}-\mathrm{t}_{5}\right) / \mathrm{r}_{1} \sin \theta_{1} \Phi \\ \mathrm{E} & \left(\mathrm{t}_{1}-\mathrm{t}_{3}\right) / 2 \mathrm{~h} & \left(\mathrm{t}_{0}-\mathrm{t}_{4}\right) / 2 \mathrm{r}_{1} \Theta & \left(\mathrm{t}_{5}-\mathrm{t}_{2}\right) / \mathrm{r}_{1} \sin \theta_{1} \Phi\end{array}$

Note that $\mathrm{T}=+-\mathrm{B} ; \mathrm{N}=+-\mathrm{S}$ and $\mathrm{W}=+-\mathrm{E}$ in each case, so it is enough to know $(\mathrm{T}, \mathrm{N}, \mathrm{W})$.

The general form is:

$s^{2}=\left[\left(t_{5}-t_{2}\right) / d_{25}\right]^{2}+\left[\left(t_{4}-t_{0}\right) / 2 d_{02}\right]^{2}+\left[\left(t_{3}-t_{1}\right) / 2 d_{12}\right]^{2}$

And we solve for $t_{5}$

$\left[\left(\mathrm{t}_{5}-\mathrm{t}_{2}\right) / \mathrm{d}_{25}\right]^{2}=\mathrm{s}^{2}-\left[\left(\mathrm{t}_{4}-\mathrm{t}_{0}\right) / 2 \mathrm{~d}_{02}\right]^{2}-\left[\left(\mathrm{t}_{3}-\mathrm{t}_{1}\right) / 2 \mathrm{~d}_{12}\right]^{2}$

$\mathrm{t}_{4}=\mathrm{t}_{2}+\mathrm{d}_{25}\left(\mathrm{~s}^{2}-\left[\left(\mathrm{t}_{4}-\mathrm{t}_{0}\right) / 2 \mathrm{~d}_{02}\right]^{2}-\left[\left(\mathrm{t}_{3}-\mathrm{t}_{1}\right) / 2 \mathrm{~d}_{12}\right]^{2}\right)^{1 / 2}$

$\mathrm{t}_{5}=\mathrm{t}_{2}+\mathrm{d}_{25}\left(\mathrm{~s}^{2}-0.25 *\left(\left(\mathrm{t}_{4}-\mathrm{t}_{0}\right)^{2} / \mathrm{d}_{02}{ }^{2}+\left(\mathrm{t}_{1}-\mathrm{t}_{3}\right)^{2} / \mathrm{d}_{12}{ }^{2}\right)\right)^{1 / 2}$

$\begin{array}{llll} & \mathrm{d}_{02} & \mathrm{~d}_{12} & \mathrm{~d}_{25} \\ \mathrm{~T} & \mathrm{r}_{2} \Theta & \mathrm{r}_{2} \sin \theta_{1} \Phi & \mathrm{h} \\ \mathrm{N} & \mathrm{h} & \mathrm{r}_{1} \sin \theta_{2} \Phi & \mathrm{r}_{1} \Theta \\ \mathrm{W} & \mathrm{r}_{1} \Theta & \mathrm{h} & \mathrm{r}_{1} \sin \theta_{1} \Phi\end{array}$


Top Side

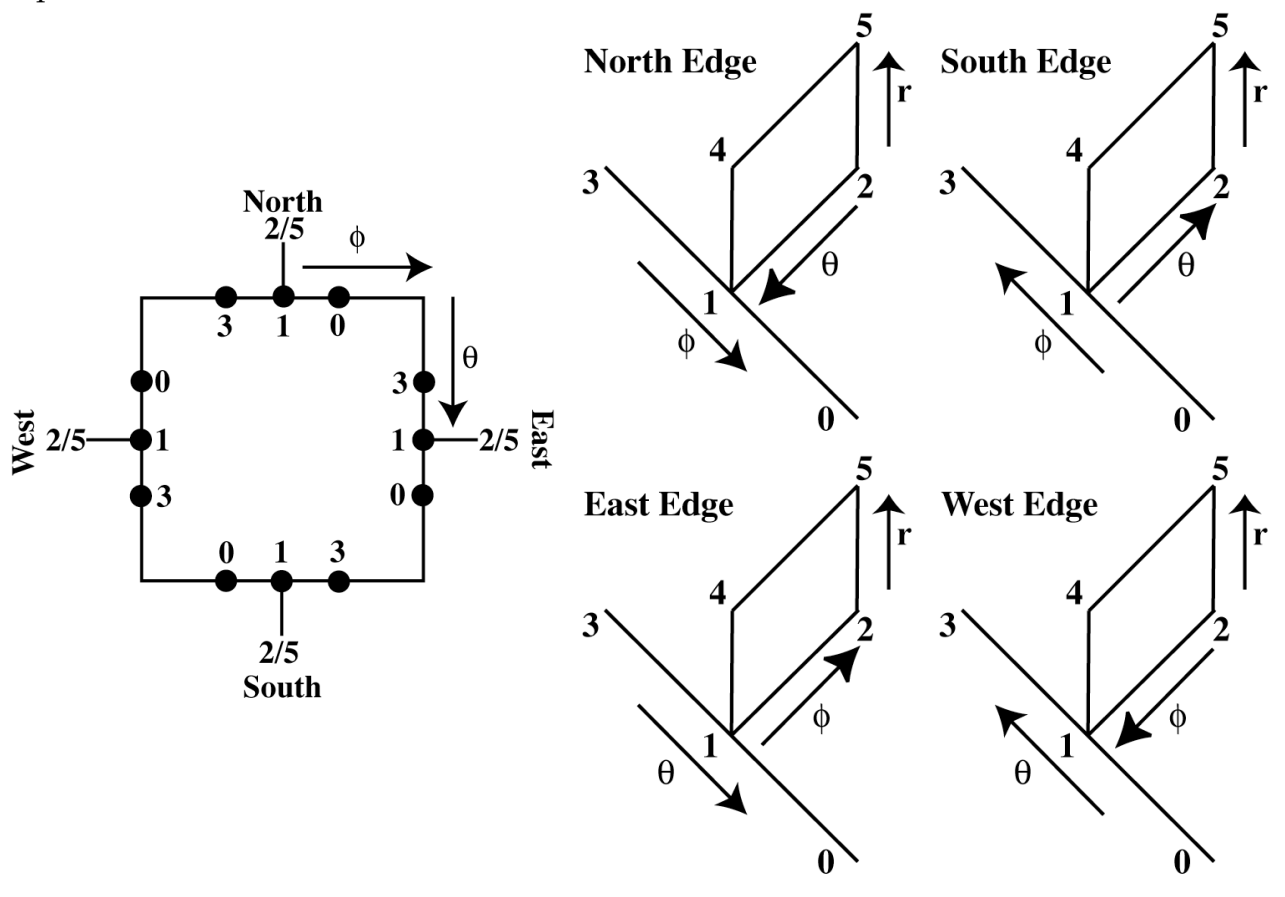

Bottom Side

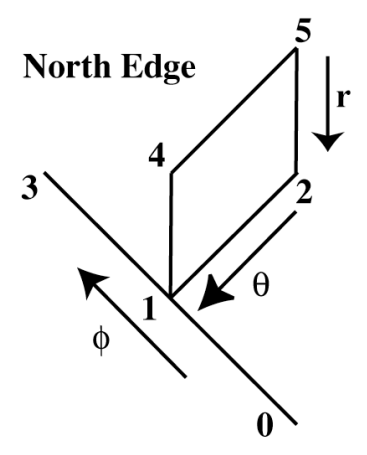


Top Side
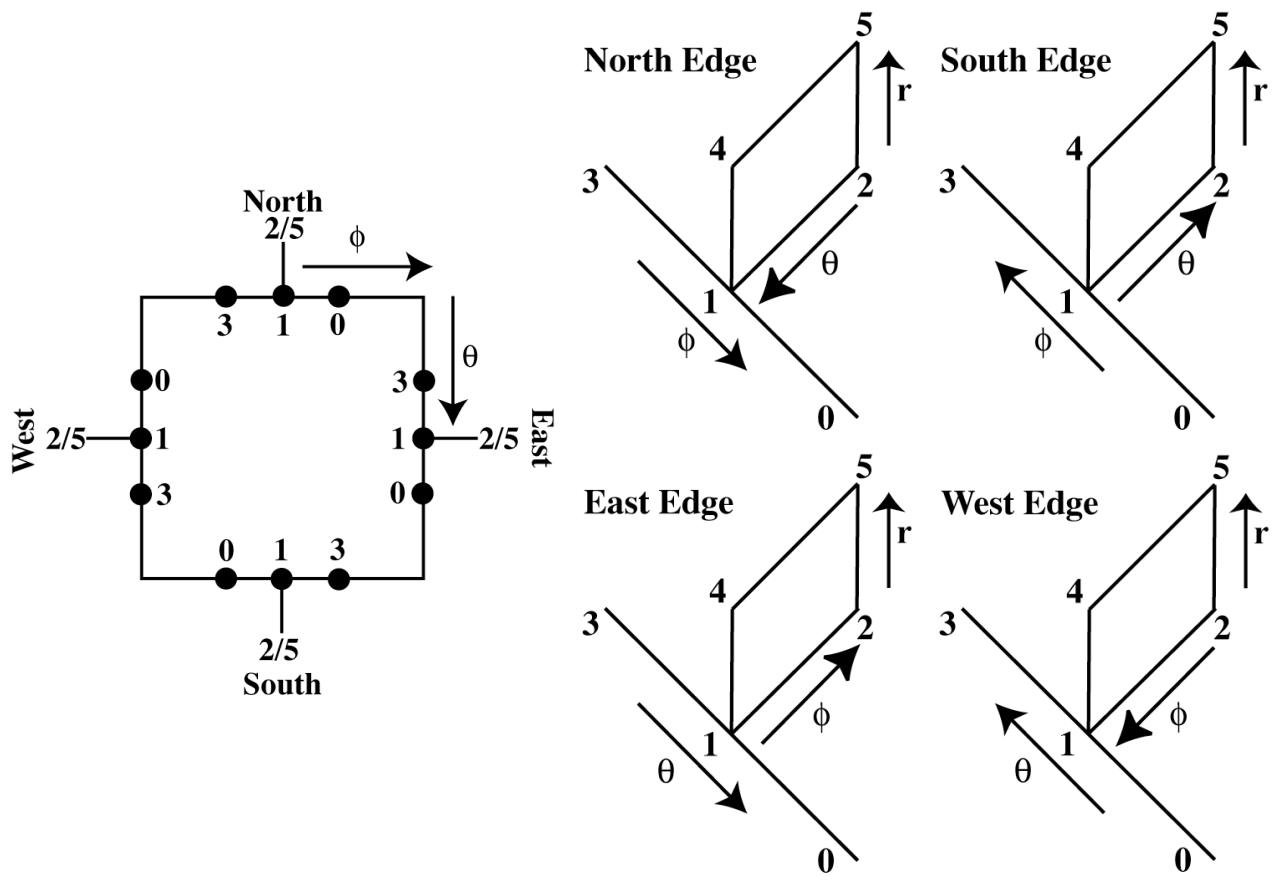
Bottom Side
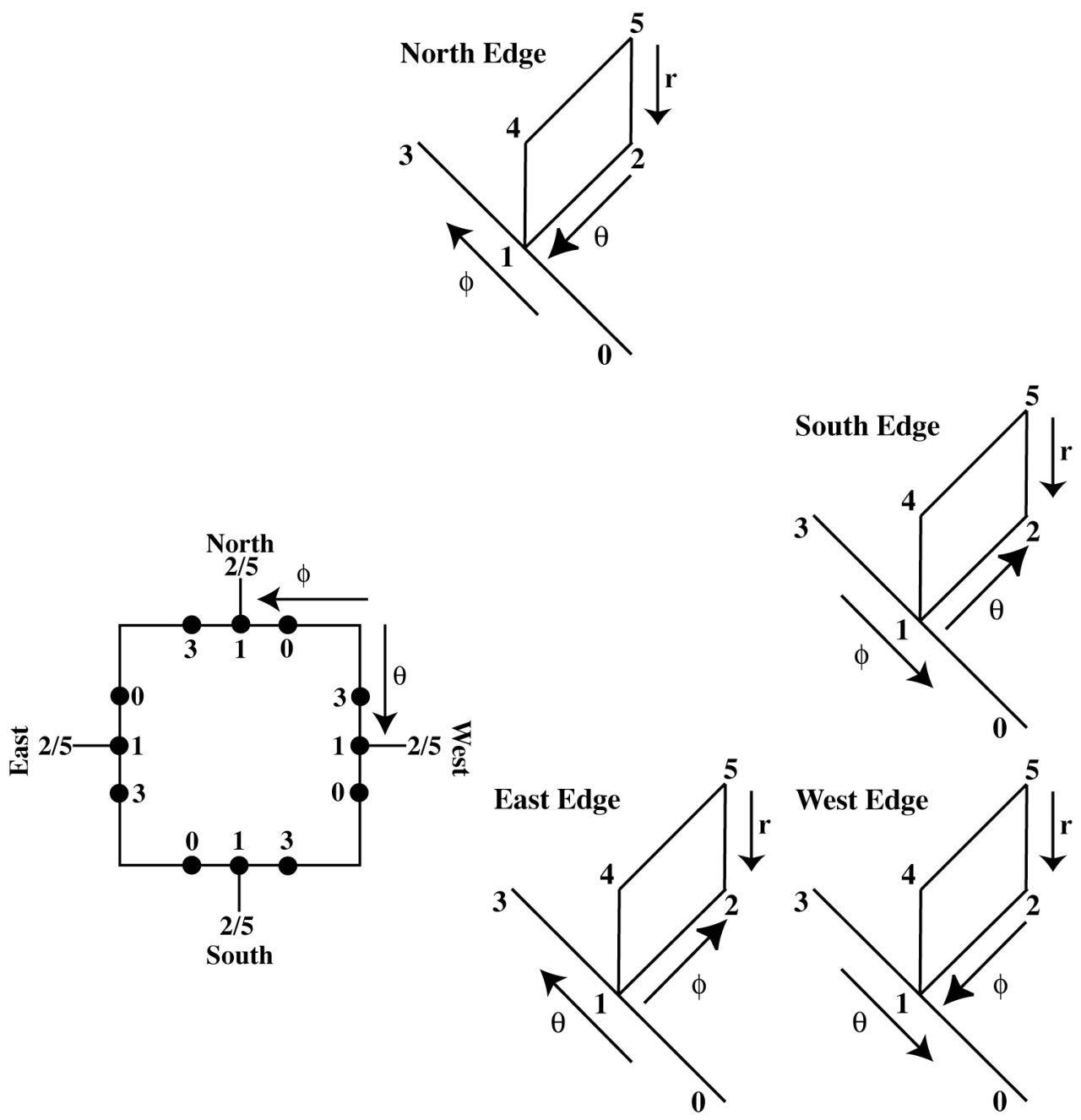
North Side

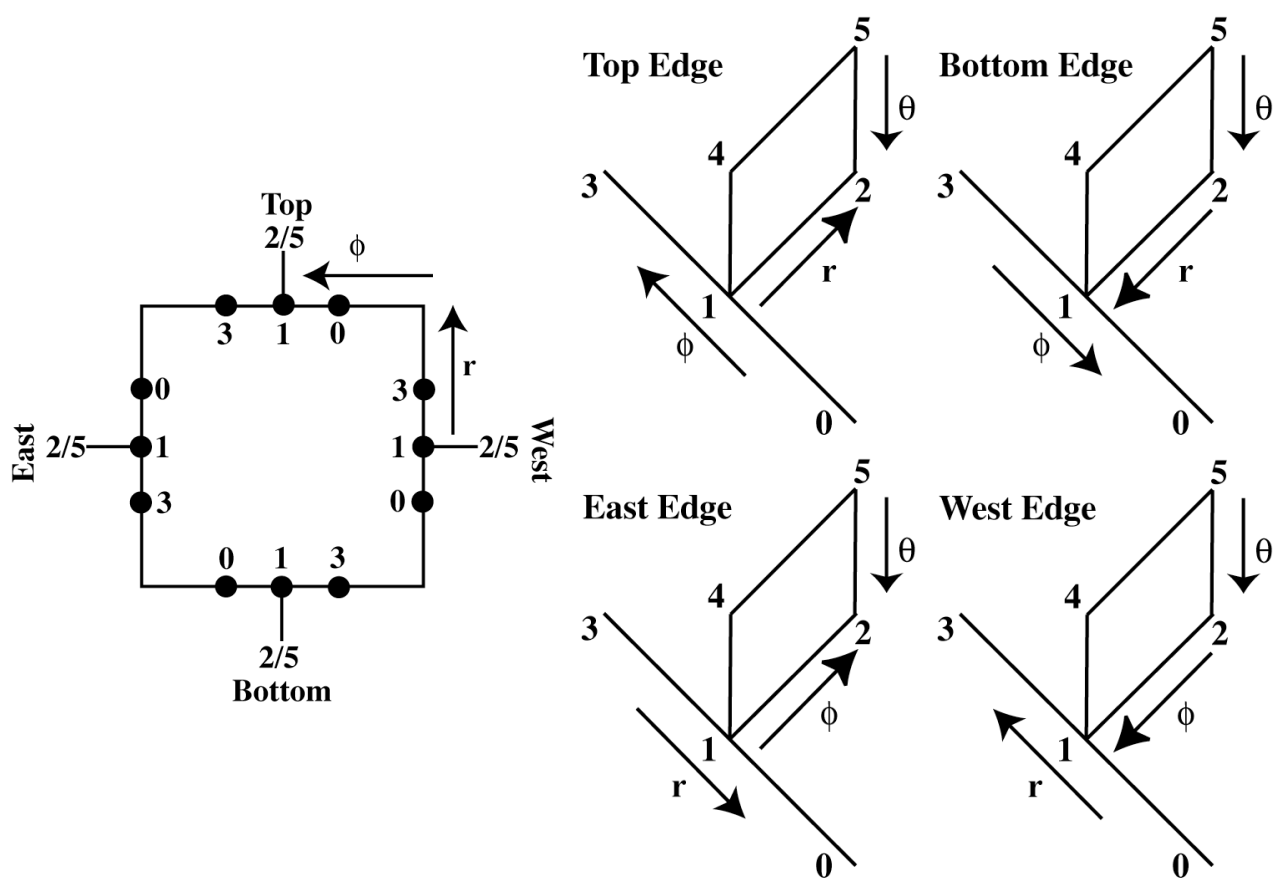


South Side

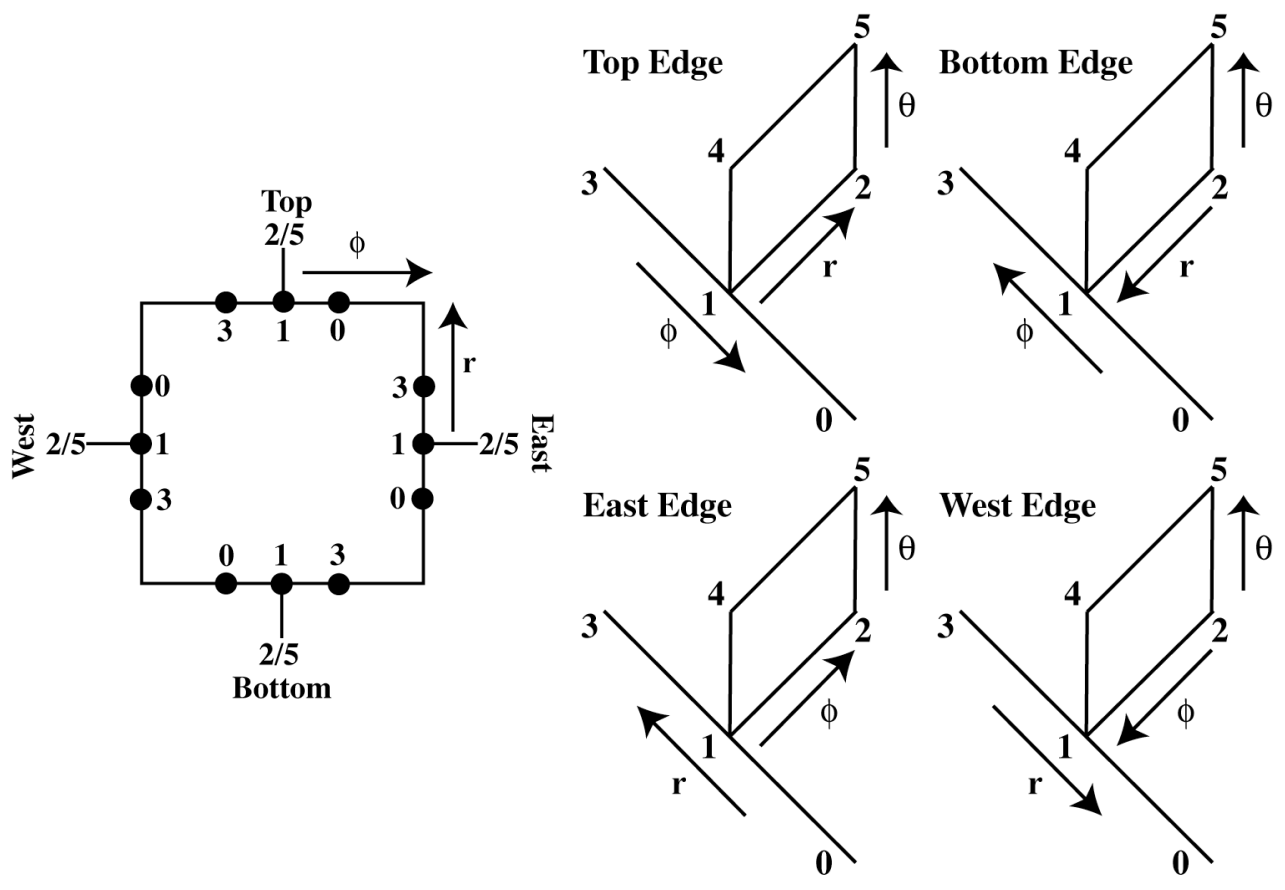


West Side
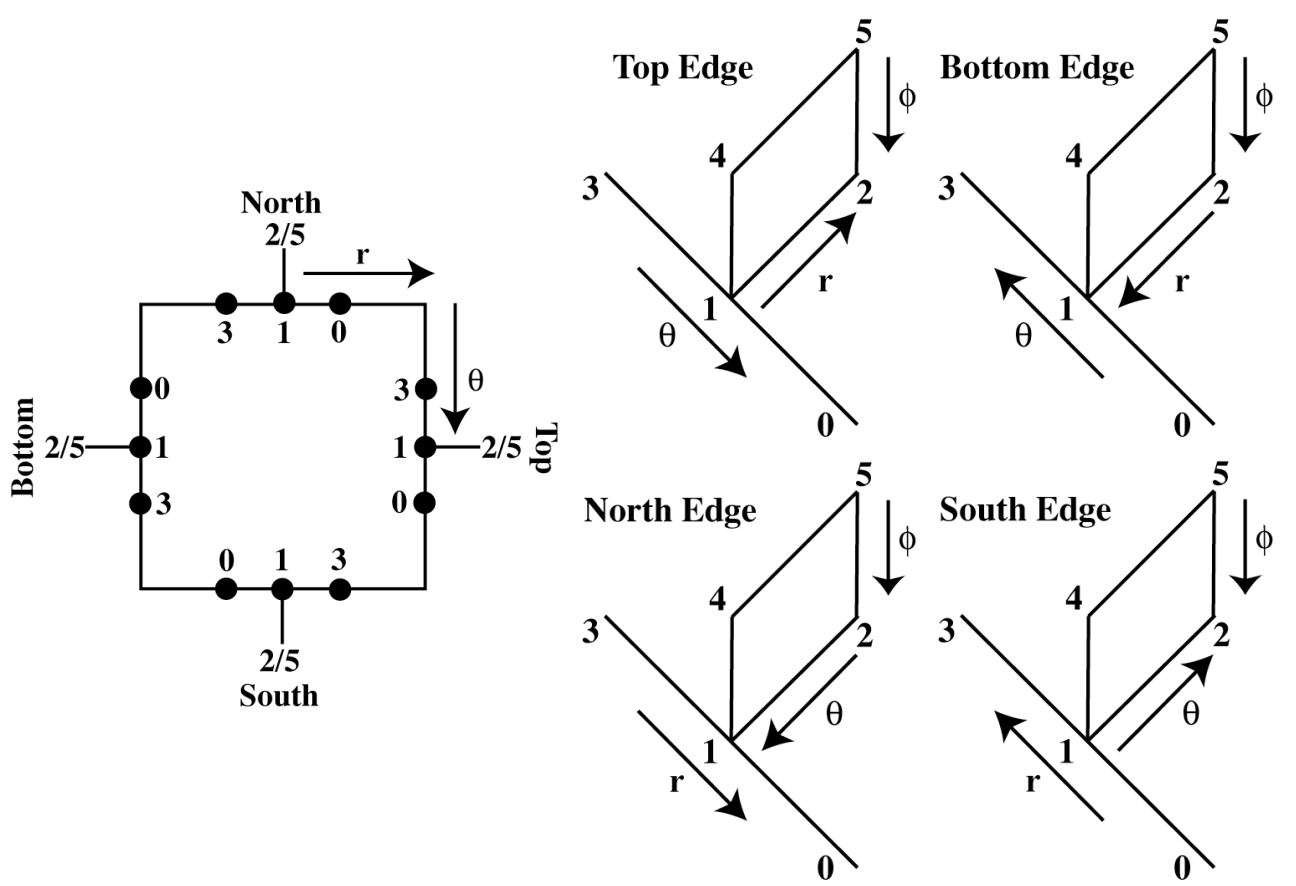
East Side

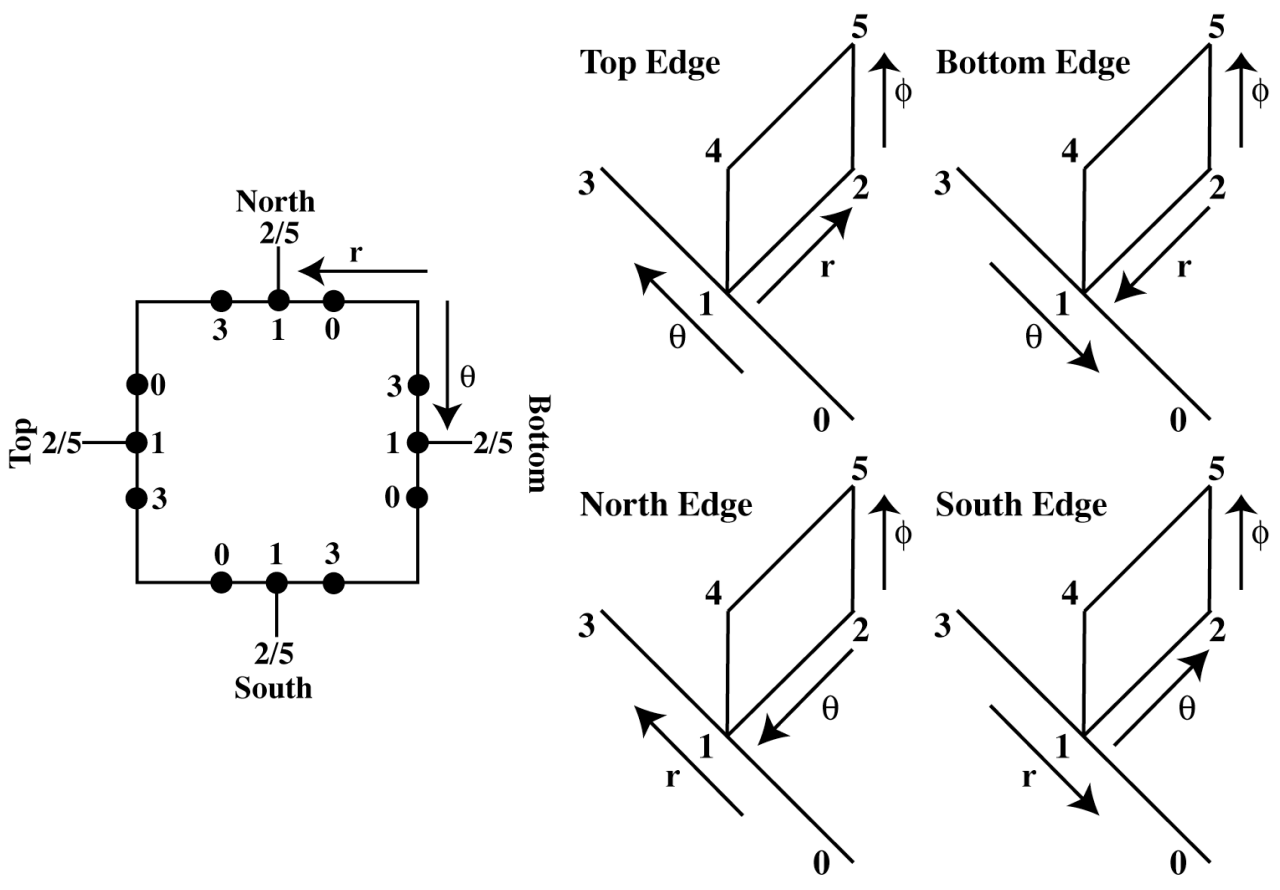


New Face Stencils

\section{East Side}
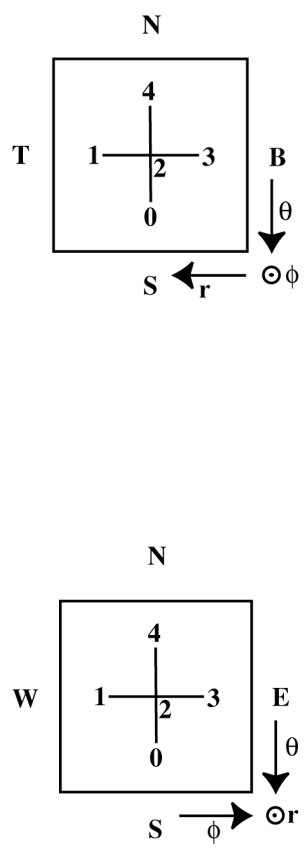

Top Side
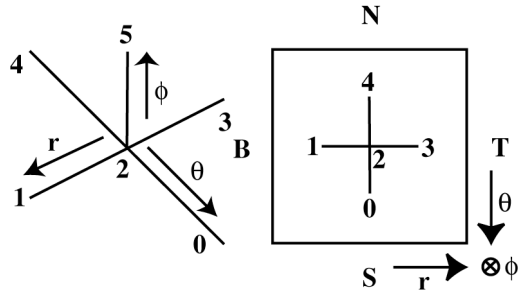

\section{West Side}

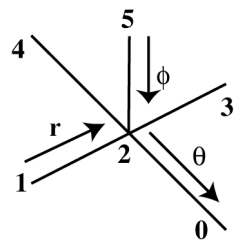

Bottom Side

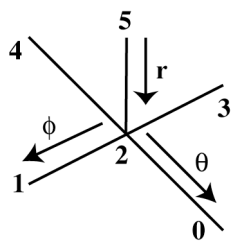

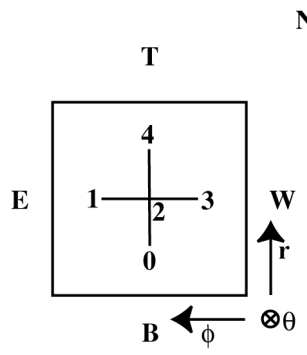

North Side
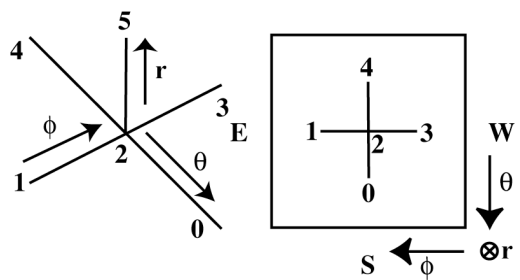
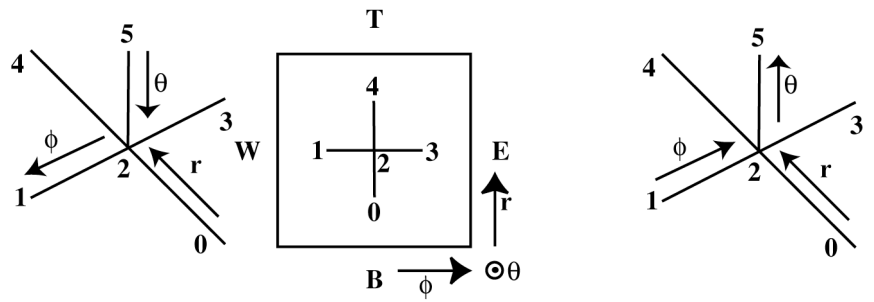

South Side 


\section{Two dimensional stencils}

For each edge there are 8 stencils: 4 parallel to the face and 4 perpendicular to the face. We number the nodes $\left(t_{0}, t_{1}, t_{2}, t_{3}\right)$, with $t_{0}$ being the unknown, $t_{1}, t_{2}$ being the adjacent points and $t_{3}$ being at the opposite corner.

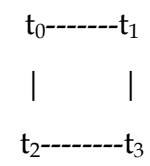

The perpendicular stencils all have (0-2) as a common edge, and the parallel stencils all have point 0 in common and either (0-1) or (0-2) as a common edge.

It is easy to show that in each case the Eikonal equation can be written as:

$4 s^{2}=\left[\left(t_{0}-t_{2}\right) / d_{02}+\left(t_{1}-t_{3}\right) / d_{13}\right]^{2}+\left[\left(t_{1}-t_{0}\right) / d_{01}+\left(t_{3}-t_{2}\right) / d_{23}\right]^{2}$

And so the solution consists of solving for $\mathrm{t} 0$ and identifying the proper distances (d01, etc) in each case. To solve for $t 0$ :

$4 s^{2}=\left(t_{0}^{2}+t_{2}^{2}-2 t_{2} t_{0}\right) / d_{02}{ }^{2}+\left[\left(t_{1}-t_{3}\right) / d_{13}\right]^{2}+2\left(t_{0} t_{1}-t_{0} t_{3}-t_{1} t_{2}+t_{2} t_{3}\right) / d_{02} d_{13}+$

$\left(t_{0}^{2}+t_{1}^{2}-2 t_{1} t_{0}\right) / d_{01}^{2}+\left[\left(t_{3}-t_{2}\right) / d_{23}\right]^{2}+2\left(t_{0} t_{2}-t_{0} t_{3}-t_{1} t_{2}+t_{1} t_{3}\right) / d_{01} d_{23}$

Isolating $\mathrm{t}_{0}$ :

$$
\begin{aligned}
& 4 s^{2}=\left(t_{0}^{2}-2 t_{2} t_{0}\right) / d_{02^{2}}+2\left(t_{0} t_{1}-t_{0} t_{3}\right) / d_{02} d_{13}+\left(t_{0}^{2}-2 t_{1} t_{0}\right) / d_{01}{ }^{2}+2\left(t_{0} t_{2}-t_{0} t_{3}\right) / d_{01} d_{23}+ \\
& \left(\mathrm{t}_{2}{ }^{2}\right) / \mathrm{d}_{02}{ }^{2}+\left[\left(\mathrm{t}_{1}-\mathrm{t}_{3}\right) / \mathrm{d}_{13}\right]^{2}+2\left(-\mathrm{t}_{1} \mathrm{t}_{2}+\mathrm{t}_{2} \mathrm{t}_{3}\right) / \mathrm{d}_{02} \mathrm{~d}_{13}+ \\
& \left(t_{1}{ }^{2}\right) / d_{01}{ }^{2}+\left[\left(t_{3}-t_{2}\right) / d_{23}\right]^{2}+2\left(-t_{1} t_{2}+t_{1} t_{3}\right) / d_{01} d_{23} \\
& 4 \mathrm{~s}^{2}=\left(\mathrm{t}_{0}^{2}\right) / \mathrm{d}_{02^{2}}+\left(\mathrm{t}_{0}{ }^{2}\right) / \mathrm{d}_{01^{2}}+ \\
& 2 t_{0}\left[\left(-t_{2}\right) / d_{02}{ }^{2}+\left(t_{1}-t_{3}\right) / d_{02} d_{13}+\left(-t_{1}\right) / d_{01}{ }^{2}+\left(t_{2}-t_{3}\right) / d_{01} d_{23}\right]+ \\
& \left(t_{2}{ }^{2}\right) / d_{02}+\left[\left(t_{1}-t_{3}\right) / d_{13}\right]^{2}+2 t_{2}\left(-t_{1}+t_{3}\right) / d_{02} d_{13}+ \\
& \left(\mathrm{t}_{1}^{2}\right) / \mathrm{d}_{01}{ }^{2}+\left[\left(\mathrm{t}_{3}-\mathrm{t}_{2}\right) / \mathrm{d}_{23}\right]^{2}+2 \mathrm{t}_{1}\left(-\mathrm{t}_{2}+\mathrm{t}_{3}\right) / \mathrm{d}_{01} \mathrm{~d}_{23} \\
& 4 s^{2}=t_{0}^{2}\left[1 / d_{02^{2}}+1 / d_{01}{ }^{2}\right]-2 t_{0}\left[t_{2} / d_{02}{ }^{2}+\left(t_{3}-t_{1}\right) / d_{02} d_{13}+\left(t_{1}\right) / d_{01}{ }^{2}+\left(t_{3}-t_{2}\right) / d_{01} d_{23}\right]+ \\
& \left(t_{2}{ }^{2}\right) / d_{02}{ }^{2}+\left[\left(t_{1}-t_{3}\right) / d_{13}\right]^{2}+2 t_{2}\left(t_{3}-t_{1}\right) / d_{02} d_{13}+ \\
& \left(t_{1}{ }^{2}\right) / d_{01}{ }^{2}+\left[\left(t_{3}-t_{2}\right) / d_{23}\right]^{2}+2 t_{1}\left(t_{3}-t_{2}\right) / d_{01} d_{23} \\
& 4 s^{2}=t_{0}^{2}\left[1 / d_{02^{2}}+1 / d_{01}{ }^{2}\right]-2 t_{0}\left[\left(t_{2} / d_{02}+\left(t_{3}-t_{1}\right) / d_{13}\right) / d_{02}+\left(t_{1} / d_{01}+\left(t_{3}-t_{2}\right) / d_{23}\right) / d_{01}\right]+ \\
& {\left[\mathrm{t}_{2} / \mathrm{d}_{02}+\left(\mathrm{t}_{3}-\mathrm{t}_{1}\right) / \mathrm{d}_{13}\right]^{2}+\left[\mathrm{t}_{1} / \mathrm{d}_{01}+\left(\mathrm{t}_{3}-\mathrm{t}_{2}\right) / \mathrm{d}_{23}\right]^{2}} \\
& 4 s^{2}=t_{0}^{2}\left[1 / d_{02}{ }^{2}+1 / d_{01}^{2}\right]+2 t_{0}\left[\left(\left(t_{1}-t_{3}\right) / d_{13}-t_{2} / d_{02}\right) / d_{02}+\left(\left(t_{2}-t_{3}\right) / d_{23}-t_{1} / d_{01}\right) / d_{01}\right]+ \\
& {\left[\left(t_{1}-t_{3}\right) / d_{13}-t_{2} / d_{02}\right]^{2}+\left[\left(t_{2}-t_{3}\right) / d_{23}-t_{1} / d_{01}\right]^{2}}
\end{aligned}
$$

Which is quadratic for $t_{0}$ :

$\mathrm{a}=1 / \mathrm{d}_{02^{2}}+1 / \mathrm{d}_{01^{2}}$

$\left.b=2^{*}\left[\left(t_{1}-t_{3}\right) / d_{13}-t_{2} / d_{02}\right) / d_{02}+\left(\left(t_{2}-t_{3}\right) / d_{23}-t_{1} / d_{01}\right) / d_{01}\right]$

$c=\left[\left(t_{1}-t_{3}\right) / d_{13}-t_{2} / d_{02}\right]^{2}+\left[\left(t_{2}-t_{3}\right) / d_{23}-t_{1} / d_{01}\right]^{2}-4 s^{2}$ 
Perpendicular Stencils:

$\begin{array}{llllll} & & \mathrm{d}_{01} & \mathrm{~d}_{02} & \mathrm{~d}_{13} & \mathrm{~d}_{23} \\ \mathrm{~T} / \mathrm{B} & \mathrm{NS} & \mathrm{r}_{1} \Theta & \mathrm{h} & \mathrm{h} & \mathrm{r}_{2} \Theta \\ & \mathrm{EW} & \mathrm{r}_{1} \sin \theta \Phi & \mathrm{h} & \mathrm{h} & \mathrm{r}_{2} \sin \theta \Phi \\ \mathrm{E} / \mathrm{W} & \mathrm{TB} & \mathrm{h} & \mathrm{r} \sin \theta_{1} \Phi & \mathrm{r} \sin \theta_{2} \Phi & \mathrm{h} \\ & \mathrm{NS} & \mathrm{r}_{1} \Theta & \mathrm{r} \sin \theta_{1} \Phi & \mathrm{r} \sin \theta_{2} \Phi & \mathrm{r}_{2} \Theta \\ \mathrm{N} / \mathrm{S} & \mathrm{TB} & \mathrm{h} & \mathrm{r}_{1} \Theta & \mathrm{r}_{2} \Theta & \mathrm{h} \\ & \mathrm{EW} & \mathrm{r} \sin \theta_{1} \Phi & \mathrm{r}_{1} \Theta & \mathrm{r}_{2} \Theta & \mathrm{r} \sin \theta_{2} \Phi\end{array}$

Parallel Stencils:

$\begin{array}{lllll} & \mathrm{d}_{01} & \mathrm{~d}_{02} & \mathrm{~d}_{13} & \mathrm{~d}_{23} \\ \mathrm{~T} / \mathrm{B} & \mathrm{r} \sin \theta \Phi & \mathrm{r}_{1} \Theta & \mathrm{r}_{1} \Theta & \mathrm{r} \sin \theta_{2} \Phi \\ \mathrm{E} / \mathrm{W} & \mathrm{h} & \mathrm{r}_{1} \Theta & \mathrm{r}_{2} \Theta & \mathrm{h} \\ \mathrm{N} / \mathrm{S} & \mathrm{r} \sin \theta_{1} \Phi & \mathrm{h} & \mathrm{h} & \mathrm{r}_{2} \sin \theta \Phi\end{array}$

Top and Bottom Faces. Stencils for the Top face shown below. Bottom differs only in sign of $\mathrm{r}$ and $\theta$.
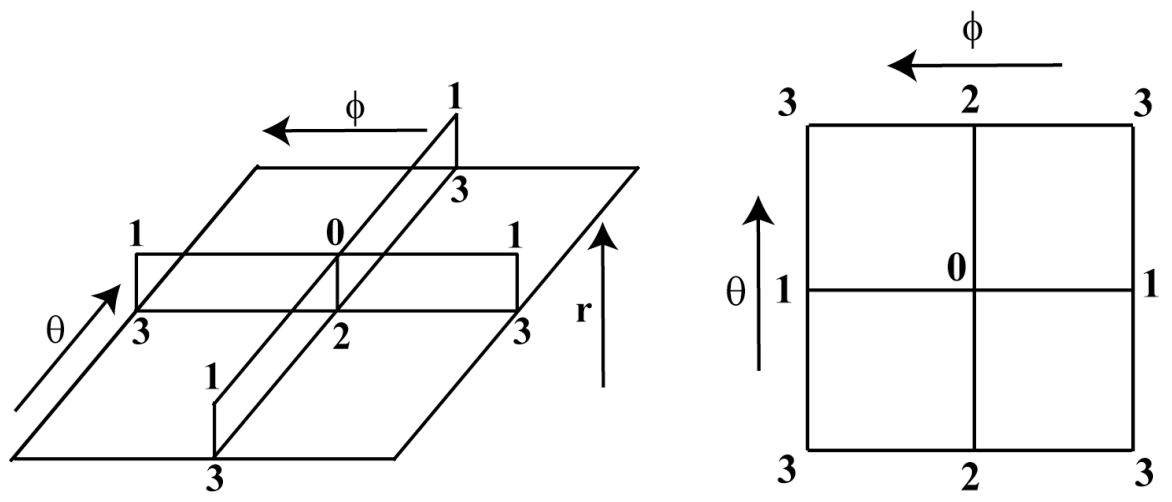
North and South Faces. Stencils for the North face shown below. South differs only in sign of $\phi$ and $\theta$.
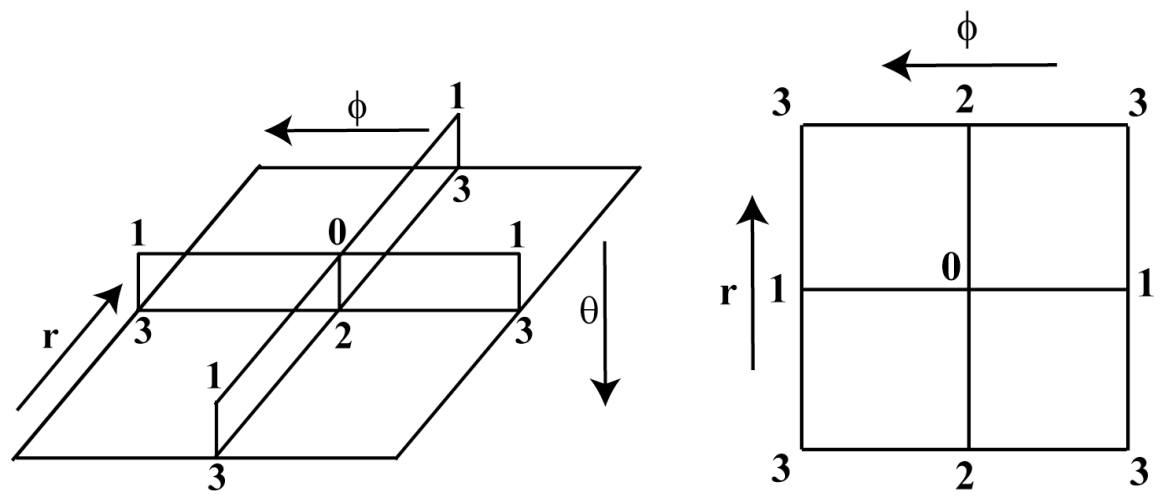

West and East Faces. Stencils for the West face shown below. East differs only in sign of $\phi$ and $r$.
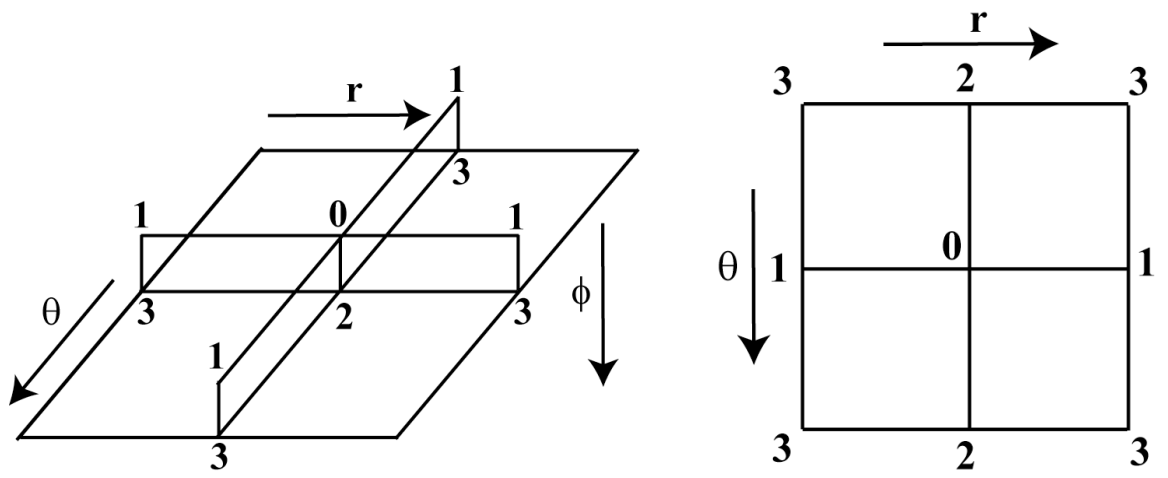

One Dimensional Stencils

Change in $\mathrm{r}$ :

Change in $\theta$ :

$$
\begin{aligned}
& \mathrm{t}_{0}=\mathrm{t}_{1}+\mathrm{hs} \\
& \mathrm{t}_{0}=\mathrm{t}_{1}+\mathrm{r} \Theta \mathrm{s}
\end{aligned}
$$

Change in $\phi$ :

$\mathrm{t}_{0}=\mathrm{t}_{1}+\mathrm{r} \sin \theta \Phi \mathrm{s}$

Note that this needs to be along the edge of the volume element for energy that travels along the edge, in the same way as the Cartesian coordinate system.

There are three types, depending on which variables are along the boundary. In each case we have $\left(t_{0}, t_{1}, t_{2}, t_{3}\right)$, with $t_{0}$ being the unknown, $t_{1}$, $t_{2}$ being the adjacent points and $t_{3}$ being at the opposite corner.

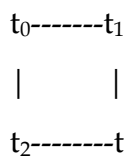




\section{References}

Abers, G.A., and Roecker, S.W. (1991), Deep structure of an arc-continent collision: earthquake relocation and inversion for upper mantle $\mathrm{P}$ and $\mathrm{S}$ wave velocities beneath Papua New Guinea, J. geophys. Res., 96, 6379-6401.

Bai, D., et al. (2010), Crustal deformation of the eastern Tibetan plateau revealed by magnetotelluric imaging, Nat. Geosci., 3, 358-362, doi:10.1038/ngeo830.

Burchfiel, B.C., L.H. Royden, R.D. van der Hilst, B.H. Hager, Z. Chen, R.W. King, C. Li, J. Lu, H. Yao, E. Kirby (2008), A geological and geophysical context for the Wenchuan earthquake of 12 May 2008, Sichuan, People's Republic of China, GSA Today, 18, 4-11.

Christensen, N.I. (1996), Poisson's ration and crustal seismology, J. Geophys. Res. 101 (B2), 3139-3156.

Clark, M. K., and L. H. Royden (2000), Topographic ooze: Building the eastern margin of Tibet by lower crustal flow, Geology, 28, 703- 706.

Eberhart-Phillips, D. (1990), Three-dimensional P and S velocity structure in the Coalinga region, California, J. Geophys. Res., 95, 15,343-15,363, doi:10.1029/ JB095iB10p15343.

Flanagan, M.P., S.C. Myers, and K.D. Koper (2007), Regional travel-time uncertainty and seismic location improvement using a three-dimensional a priori velocity model, Bull. Seismol. Soc. Am., 97, 804-825.

Fowler P.J. (1994), Finite-difference solutions of the 3D eikonal equation in spherical coordinates, 64th SEG meeting, Los Angeles, USA, Expanded Abstracts, 1394-1397.

Hole, J.A. (1992), Nonlinear high-resolution 3-dimensional seismic travel time tomography, J. Geophys. Res., 97, 6553-6562

$\mathrm{Hu}, \mathrm{S} ., \mathrm{He}, \mathrm{L}$. \& Wang, J., 2000. Heat flow in the continental area of China: a new data set, Earth planet. Sci. Lett., 179, 407-419.

Huang, R., Z. Wang, S. Pei, and Y. Wang (2009), Crustal ductile flow and its contribution to tectonic stress in southwest China, Tectonophysics, 473, 476-489.

Huang, H., H. Yao, and R. D. van der Hilst (2010), Radial anisotropy in the crust of SE Tibet and SW China from ambient noise interferometry, Geophys. Res. Lett., 37, L21310, doi:10.1029/2010GL044981.

Huang, J., D. Zhao, and S. Zheng (2002), Lithospheric structure and its relationship to seismic and volcanic activity in southwest China, J. Geophys. Res., 107(B10), 2255, doi:10.1029/2000JB000137.

Hubbard, J. and J.H. Shaw (2009), Uplift of the Longmen Shan and Tibetan plateau, and the 2008 Wenchuan $(\mathrm{M}=7.9)$ earthquake, Nature, 458, 194-197.

Jamieson, R.A., Beaumont, C., Nguyen, M.H., and Grujic, D. (2006). Provenance of the greater Himalayan Sequence and associated rocks: predictions of channel flow models. In: Law, R.D., Searle, M.P. \& Godin, L. (eds) Channel Flow, Ductile Extrusion and Exhumation in Continental Collision Zones. Geological Society, London, Special Publications, 268, 165-182.

Li, H.Y., Su, W., Wang, C.-Y., Huang, Z.X., Lv., Z.Y. (2010), Ambient noise Love wave tomography in the eastern margin of the Tibetan plateau, Tectonophysics 491, 194204.

Li, S. et al. (2003), Partial melt or aqueous fluid in the mid-crust of southern Tibet? Constraints from INDEPTH magnetotelluric data. Geophys. J. Int. 153, 289-304. 
Liu, Q.Y., Y. Li, and J.H. Chen et al. (2009), Wenchuan Ms8.0 earthquake: preliminary study of the S-wave velocity structure of the crust and upper mantle, Chinese J. Geophys., 52(2), 309-319. (in Chinese)

Meade, B.J. (2007), Present-day kinematics at the India-Asia collision zone, Geology, 35, 8184, doi:10.1130/G22942A.

Nakajima, J., T. Matsuzawa, A. Hasegawa, and D. Zhao (2001), Three-dimensional structure of $\mathrm{Vp}$, Vs, and $\mathrm{Vp} / \mathrm{Vs}$ beneath northeastern Japan: Implications for arc magmatism and fluids, J. Geophys. Res., 106, 21,843-21,857.

Nelson, K. D., et al. (1996), Partially molten middle crust beneath southern Tibet: Synthesis of project INDEPTH results, Science, 274, 1684-1688.

Nelson, G.D., and J.E. Vidale (1990), Earthquake locations by 3-D finite-difference traveltimes, Bull. Seismol. Soc. Am., 80, 395-410

Paige, C. C., and M. A. Saunders (1982). LSQR: sparse linear equations and least squares problems, ACM Trans. Math. Softw. 8, no. 2, 195-209.

Pei, S., J. Su, H. Zhang, Y. Sun, M.N. Toksoz, Z. Wang, X. Gao, J.L. Zeng, and J. He (2010), Three-dimensional seismic velocity structure across the 2008 Wenchuan Ms 8.0 earthquake, Sichuan, China, Tectonophysics, 491, 211-217.

Podvin, P. and Lecomte, I. (1991), Finite difference computation of traveltimes in very contrasted velocity models: a massively parallel approach and its associated tools., Geophys. J. Int., 105, 271-284.

Robert, A., J. Zhu, J. Vergne, R. Cattin, L.S Chan, G. Wittlinger, G. Herquel, J. de Sigoyer, M. Pubellier, and L.D. Zhu (2010), Crustal structures in the area of the 2008 Sichuan earthquake from seismologic and gravimetric data, Tectonophysics, 491, 205-210.

Rosenberg, C. L. and Handy, M. R (2005)m Experimental deformation of partially melted granite revisited: Implications for the continental crust. J. Metamorphic Geol. 555, $1-9$.

Royden, L. H., B. C. Burchfiel, W. King, E. Wang, Z. Chen, F. Shen, and Y. Liu (1997), Surface deformation and lower crustal flow in Eastern Tibet, Science, 276, 788- 790.

Shen, Z.-K., J. Lu, M. Wang, and R. Burgmann (2005), Contemporary crustal deformation around the southeast borderland of the Tibetan Plateau, J. Geophys. Res., 110, B11049, doi: 10.1029.

Schneider, W. A. (1995), Robust and efficient upwind finite-difference traveltime calculations in three dimensions, Geophysics, 60, 1108-1117.

Sun, J., Jin, G.W., Bai, D.H. and Wang, L.F. (2003), Electrical structure of the crust and upper mantle and tectonics sense on the edge of the East Tibet, Science in China (Series D) (in Chinese), 33 (Suppl.) 173- 180.

Takei, Y. (2002), Effect of pore geometry on Vp/Vs: From equilibrium geometry to crack, J. Geophys. Res., 107 (B2), 2043.

Teng. J.W., D.H. Bai, H. Yang, et al. (2008), Deep processes and dynamic responses associated with the Wenchuan Ms8.0 earthquake of 2008, Chinese J. Geophys. (in Chinese), 51(5), 1385-1402.

Thurber, C. H. (1993), Local earthquake tomography: Velocities and Vp/Vs theory, in Seismic Tomography: Theory and Practise, edited by H. M. Iyer and K. Hirahara, pp. 563-583, Chapman and Hall, New York.

Thurber, C., and D. Eberhart-Phillips (1999), Local earthquake tomography with flexible gridding, Comput. Geosci., 25, 809-818, doi:10.1016/S0098-3004(99)00007-2. 
Vidale, J. (1988), Finite-difference calculation of travel times, Bullet. Seismol. Soc. Am., 78, 2062-2076.

Vidale, J.E. (1990), Finite-difference calculation of traveltimes in three dimensions, Geophysics, 55, 521-526.

Wagner, L. S., S. Beck, and G. Zandt (2005), Upper mantle structure in the south central Chilean subduction zone (30 to 36 S), J. Geophys. Res., 110, B01308, doi:10.1029/2004JB003238.

Wang, C.-Y., W. Winston Chan, and W.D. Mooney (2003), Three-dimensional velocity structure of crust and upper mantle in southwestern China and its tectonic implications, J. Geophys. Res., 108(B9), 2442, doi:10.1029/2002JB001973.

Wang, C.-Y., W.-B. Han, J.-P. Wu, H. Lou, and W. W. C. Chan (2007), Crustal structure beneath the eastern margin of the Tibetan Plateau and its tectonic implications, J. Geophys. Res., 112, B07307.

Wang, C.-Y., H. Lou, Z. Lu, J. Wu, L. Chang, S. Dai, H. You, F. Tang, L. Zhu, and P. Silver (2008a), S-wave crustal and upper mantle's velocity structure in the eastern Tibetan Plateau - Deep environment of lower crustal flow, Sci. China Ser. D-Earth Sci., 51, 263-274.

Wang, W.M., L.F. Zhao, J. Li, and Z.X. Yao (2008b), Rupture process of the Ms 8.0 Wenchuan earthquake of Sichuan, China, Chinese J. Geophys. (in Chinese), 51(5), 1403-1410.

Wang, X.B., X.T. Zhu, N. Yu, et al. (2008), Magnetotelluric sounding new evidence to thrust belt structure in LongmenShan, submitted to Chinese J. Geophys. (in Chinese).

Wang, Z., Y. Fukao, and S. Pei (2009), Structural control of rupturing of the Mw 7.92008 Wenchuan earthquake, China, Earth Planet. Sci. Lett., 279, 131-138.

Wei, W., M. Unsworth, A. Jones, J. Booker, H. Tan, D. Nelson, L. Chen, S. Li, K. Solon, P. Bedrosian, S. Jin, M. Deng, J. Ledo, D. Kay, and B. Roberts (2001), Detection of widespread fluids in the Tibetan crust by magnetotelluric studies, Science, 292, 716718 .

Xu, L., S. Rondenay, R.D. van der Hilst (2007), Structure of the crust beneath the southeastern Tibetan Plateau from teleseismic receiver functions, Phys. Earth Planet. Int., 165, 176-193.

Xu, Z.J. and X. Song (2010), Joint inversion for crustal and Pn velocities and Moho depth in Eastern Margin of the Tibetan Plateau, Tectonophysics, 491, 185-193.

Yao, H., C. Beghein, and R.D. van der Hilst (2008), Surface wave array tomography in SE Tibet from ambient seismic noise and two-station analysis - II. Crustal and uppermantle structure, Geophys. J. Int., 173, 205-219.

Yao, H., R. D. van der Hilst, and J.-P. Montagner (2010), Heterogeneity and anisotropy of the lithosphere of SE Tibet from surface wave array tomography, J. Geophys. Res., 115, B12307, doi:10.1029/2009JB007142.

Zhang, H., and C. H. Thurber (2003), Double-Difference Tomography: The Method and Its Application to the Hayward Fault, California, Bull. Seism. Soc. Am, 93, 1875-1889.

Zhang, H., S. Sarkar, M.N. Toksoz, H.S. Kuleli, and F. Al-Kindy (2009a), Passive seismic tomography using induced seismicity at a petroleum field in Oman, Geophysics, 74(6), WCB67, doi:10.1190/1.3253059.

Zhang, H., C.H. Thurber, and P. Bedrosian (2009b), Joint inversion for Vp, Vs, and Vp/Vs at SAFOD, Parkfield, California, Geochemistry, Geophysics, Geosystems, 10, Q11002, doi:10.1029/2009GC002709. 
Zhang, P.Z., X.W. Xu, X.Z. Wen, et al. (2008), Slip rate and recurrence interval of the Longmen Shan active fault zone, and tectonic implications for the mechanism of the May 12 Wenchuan earthquake, 2008, Sichuan, China, Chinese J. Geophys. 51(4), 1066-1073. (in Chinese)

Zhang, Z., Y. Wang, Y. Chen, G. A. Houseman, X. Tian, E. Wang, and J. Teng (2009c), Crustal structure across Longmenshan fault belt from passive source seismic profiling, Geophys. Res. Lett., 36, L17310, doi:10.1029/2009GL039580.

Zhao, G., X. Chen, L. Wang, J. Wang, J. Tang, Z. Wan, J. Zhang, Y. Zhan, and Q. Xiao (2008), Evidence of crustal 'channel flow' in the eastern margin of Tibetan Plateau from MI measurements, Chinese Sciences Bulletin, 53, 1887-1893.

Zhao, Z. J. Fang, and S. Zhen (1997), Crustal velocity and relocated events in the Longmen Shan fault zone, Acta Seismol. Sin., 19, 615-612 (in Chinese) 


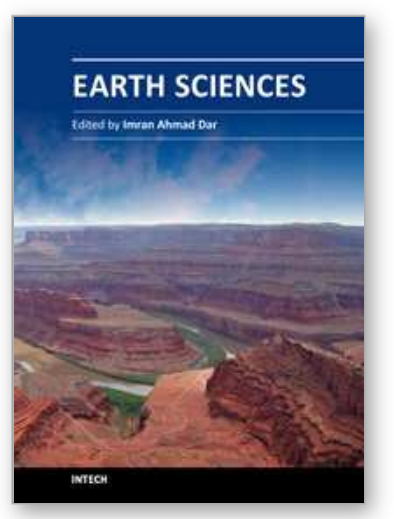

\author{
Earth Sciences \\ Edited by Dr. Imran Ahmad Dar
}

ISBN 978-953-307-861-8

Hard cover, 648 pages

Publisher InTech

Published online 03, February, 2012

Published in print edition February, 2012

The studies of Earth's history and of the physical and chemical properties of the substances that make up our planet, are of great significance to our understanding both of its past and its future. The geological and other environmental processes on Earth and the composition of the planet are of vital importance in locating and harnessing its resources. This book is primarily written for research scholars, geologists, civil engineers, mining engineers, and environmentalists. Hopefully the text will be used by students, and it will continue to be of value to them throughout their subsequent professional and research careers. This does not mean to infer that the book was written solely or mainly with the student in mind. Indeed from the point of view of the researcher in Earth and Environmental Science it could be argued that this text contains more detail than he will require in his initial studies or research.

\title{
How to reference
}

In order to correctly reference this scholarly work, feel free to copy and paste the following:

Haijiang Zhang, Steve Roecker, Clifford H. Thurber and Weijun Wang (2012). Seismic Imaging of Microblocks and Weak Zones in the Crust Beneath the Southeastern Margin of the Tibetan Plateau, Earth Sciences, Dr. Imran Ahmad Dar (Ed.), ISBN: 978-953-307-861-8, InTech, Available from:

http://www.intechopen.com/books/earth-sciences/seismic-imaging-of-microblocks-and-weak-zones-in-thecrust-beneath-the-southeastern-margin-of-the-ti

\section{INTECH}

open science | open minds

\section{InTech Europe}

University Campus STeP Ri

Slavka Krautzeka 83/A

51000 Rijeka, Croatia

Phone: +385 (51) 770447

Fax: +385 (51) 686166

www.intechopen.com

\section{InTech China}

Unit 405, Office Block, Hotel Equatorial Shanghai

No.65, Yan An Road (West), Shanghai, 200040, China

中国上海市延安西路65号上海国际贵都大饭店办公楼405单元

Phone: +86-21-62489820

Fax: $+86-21-62489821$ 
(C) 2012 The Author(s). Licensee IntechOpen. This is an open access article distributed under the terms of the Creative Commons Attribution 3.0 License, which permits unrestricted use, distribution, and reproduction in any medium, provided the original work is properly cited. 